\title{
LA APLICACIÓN DEL PRINCIPIO DE PRECAUCIÓN EN EL SECTOR ENERGÉTICO NUCLEAR. LA DIALÉCTICA ENTRE GARANTÍA DE SUMINISTRO Y RIESGO
}

\author{
Miguel Ángel Guirado EspinOsA \\ Doctorando en Derecho \\ Universitat Rovira i Virgili \\ mguiradoespinosa@gmail.com
}

Recibido: 26 de febrero de 2015 / Aceptado: 23 de marzo de 2015

RESUMEN: El dilema entre el desarrollo tecnológico y la admisibilidad del riesgo asociado tiene como ejemplo paradigmático a la industria energética nuclear. En la actualidad, este dilema se ha fortalecido debido, por una parte, al accidente de Fukushima de 2011 -que volvió a evidenciar el riesgo asociado a la industria energética nuclear- $\mathrm{y}$, por otra, a la apreciación de la energía nuclear como alternativa energética a los hidrocarburos, en correspondencia con la lucha contra los gases de efecto invernadero. Asimismo, el dilema para los Estados que hacen uso de la energía nuclear se evidencia también en el aspecto estratégico de una energía que garantiza la seguridad del suministro eléctrico. En este trabajo se ha analizado esta dialéctica tomando como instrumento jurídico el principio de precaución, por cuanto que permite valorar la admisibilidad del riesgo indeterminado tanto en sus probabilidades como en sus consecuencias. En última instancia se ha analizado también la legitimidad de la decisión final sobre la admisibilidad del riesgo, en contraposición a la decisión basada únicamente en la valoración de los expertos.

RESUM: El dilema entre el desenvolupament tecnològic i l'admissibilitat del risc que se li associa té com a exemple paradigmàtic la indústria energètica nuclear. Actualment, aquest dilema s'ha intensificat a causa, d'una banda, de l'accident de Fukushima de 2011 — que va tornar a evidenciar el risc associat a la industria energètica nuclear- i, de l'altra, a l'apreciació de l'energia nuclear com alternativa energètica als 
hidrocarburs, en correspondència amb la lluita contra els gasos d'efecte hivernacle. Així mateix, el dilema para els estats que fan ús de l'energia nuclear s'evidencia també en l'aspecte estratègic d'una energia que garanteix la seguretat del subministrament elèctric. En aquest treball s'ha analitzat aquesta dialèctica, prenent com a instrument jurídic el principi de precaució, que permet valorar l'admissibilitat del risc indeterminat tant en les seves probabilitats com en les seves conseqüències. En darrera instància, s'ha analitzat també la legitimitat de la decisió final sobre l'admissibilitat del risc, en contraposició a la decisió basada únicament en la valoració dels experts.

ABSTRACT: The nuclear energy industry poses a paradigmatic example for the dilemma between technological development and the admissibility of the associated risks. This dilemma is presently reinvigorating, as the 2011 Fukushima accident stressed once again the associated risks, against persistent perceptions of nuclear energy as a valuable alternative to fossil energy sources, especially in view of climate change mitigation. Likewise, states that use nuclear energy also face this dilemma from its strategic point of view, as an energy source that ensures safety of supply. This article appraises these dialectics from the point of view of the precautionary principle, as it allows assessing the admissibility of the undetermined risks in terms of both, their probability and consequences. Ultimately, this article also elucidates the legitimacy of the final decision on the admissibility of the risks, as opposed to the decision based only on the judgment of the experts.

PALABRAS CLAVE: principio de precaución —energía nuclear — riesgo — garantía de suministro-legitimidad democrática.

PARAULES CLAU: Principi de precaució - Energina nuclear - Risc - Garantia de subministrament — Legimitat democrática.

KEYWORDS: Precautionary Principle - Nuclear Energy - Risk — Security of supply - Democratic Legitimacy. 
SUMARIO: I. Planteamiento inicial. Una breve introducción a la cuestión nuclear. II. Un acercamiento al principio de precaución. La ponderación entre riesgo y beneficio obtenido. III. La incertidumbre en la valoración de los riesgos asociados a la generación de electricidad de origen nuclear. La aplicación del principio de precaución en el sector. 1. La incertidumbre en cuanto a la seguridad de las instalaciones nucleares. 2. La incertidumbre respecto a la gestión de los residuos nucleares. La afectación a las generaciones futuras. 3. El problema de la proliferación armamentística nuclear. 4. El coste de la generación energética nuclear. 5. La aplicación del principio de precaución en la industria energética nuclear. IV. La dialéctica entre el riesgo y el beneficio. La energía nuclear como garantía de suministro eléctrico. V. La legitimidad de la decisión final. El peso de la opinión pública. VI. Conclusiones. VII. Bibliografía.

\section{PLANTEAMIENTO INICIAL. UNA BREVE INTRODUCCIÓN A LA CUESTIÓN NUCLEAR}

El profesor Ulrich BECK, en su célebre obra La sociedad del riesgo: hacia una nueva modernidad, sugiere lo siguiente:

Cuando el desarrollo tecnológico entra en contradicción con una certidumbre quizás incluso cuando resulta fundamentalmente tranquilizadora-, se le imputa a la humanidad el insoportable yugo de la infalibilidad. Al aumentar el riesgo, aumenta la inclinación a someterse a lo infalible de modo que se pierde la propia capacidad de aprender. ${ }^{1}$

Podemos extrapolar fielmente esta afirmación a los propios inicios de la industria energética nuclear. Así, el uso pacífico del potencial nuclear se inicia con la declaración "Atoms for the Peace", de 1953, con la que los EE. UU. decidieron, en palabras de Juan Manuel AYLLÓN, sustituir la "hegemonía militar nuclear" —a la postre igualada por potencias como la URSS y Reino Unido- por la "hegemonía comercial". . Lo cierto es que el Gobierno estadounidense esperaba sacar ventaja de su nueva tecnología, tanto para propósitos pacíficos como bélicos ${ }^{3}$, mediante su venta a otros Estados que pudieran estar interesados en el uso de energía nuclear de forma pacífica. De este modo nacía la industria energética nuclear en un ambiente, podríamos decir, de ingenuidad y esperanza estratégica más que de desconfianza y precaución hacia una tecnología cuyos efectos en la II Guerra Mundial habían quedado demostrados y cuya opción pacífica se

\footnotetext{
${ }^{1}$ BECK, U., La sociedad del riesgo: hacia una nueva modernidad, Paidós, Barcelona, 1998, p. 231.

${ }^{2}$ AYLlÓN DÍAZ-GONZÁLEZ, J. M., Derecho Nuclear, Comares, Granada, 1999, p. 17.

${ }^{3}$ Efectivamente, el desarrollo tecnológico de la industria de la fisión nuclear fue, en principio, para su uso militar cuyo fin era la fabricación de armamento nuclear. Para un análisis integral de las cuestiones no solo políticas, económicas y ambientales, sino también éticas y sociales de la energía nuclear, vid. SHRADER-FRECHETTE, K.S., Energía nuclear y bienestar público, Alianza, Madrid, 1980.
} 
mostraba, en cierta forma, también como una fuente de destrucción en caso de escapar al control humano.

España, dentro de este ambiente de furor nuclear ${ }^{4}$, firmó un acuerdo con los EE. UU. el 19 de julio de 1955. A partir de aquí nuestro país se lanzó a la construcción del parque nuclear que habría de resolver las necesidades energéticas del futuro ${ }^{5}$. Algunos años más tarde, el 29 de abril de 1964, surgiría nuestra todavía hoy sorprendentemente vigente Ley de Energía Nuclear —en adelante, LEN ${ }^{6}$.

En cualquier caso, hemos de entender que, para el Gobierno de entonces, lo importante era fomentar el desarrollo de una tecnología que se vislumbraba como el "maná" de la independencia energética, lo cual precisaba de una alfombra roja que facilitara el acceso del capital privado a la tecnología nuclear, además de limitar, en lo posible, la responsabilidad de los operadores nucleares. En este trabajo no entraremos a valorar en detalle los aspectos de responsabilidad de dichos operadores, pero creo que es necesario resaltar que, principalmente, se trataba de la utilización por todos los medios de dicha tecnología para la generación de energía. Todo ello basándose en la plena confianza en la tecnociencia como "gurú" del bienestar futuro.

Lo anterior se tradujo, como no podía ser de otra forma, en una relajación en lo concerniente a la seguridad de las instalaciones y a la protección frente a la radiactividad $^{7}$. Asimismo, aun habiéndose materializado en 1968 el Tratado de No Proliferación Nuclear, países como la India efectuaron pruebas militares nucleares valiéndose de tecnología occidental, lo que supuso hacer frente, además de a los problemas de la seguridad y los residuos, al de la proliferación de armamento atómico.

\footnotetext{
${ }^{4} \mathrm{La}$ fe ciega en las virtudes de esta energía fue la que llevó a Lewis Strauss, entonces presidente de la Comisión de Energía Atómica de EE. UU., a decir en 1954 que "no podía descartarse que la electricidad nuclear fuera tan barata que no mereciera la pena facturarla".

${ }^{5}$ VIANA, I., "Franco y el nacimiento de las centrales nucleares en España", $A B C$ (2011, 16 de agosto). Recuperado el 23 de enero de 2015, de http://www.abc.es/20110318/archivo/abci-franco-centralesnucleares-espaa-201103172157.html.

${ }^{6}$ AYLLÓN DÍAZ-GONZÁLEZ, J. M., Derecho..., cit., p. 34. También podemos encontrar un reciente análisis de toda la regulación del sector desde sus inicios en la obra de MORALES PLAZA, A., Regulación nuclear globalizada, La Ley, Madrid, 2009.

${ }^{7}$ Juan Manuel Ayllón afirma al respecto de la relajación en la seguridad que "fueron dos los factores que convergieron para que ello aconteciese así. De una parte, era difícil convencer al capital privado para que invirtiera en energía nuclear sobre la base de costes importantes en seguridad, sobre todo cuando no estaban demasiado claras las ganancias [...] Por otra parte, la carencia de accidentes nucleares verdaderamente graves y el desconocimiento de las consecuencias incluso científico-físicas que éstos podían causar y de los efectos de las pequeñas dosis de radiactividad sobre la salud humana, hacían pensar ingenuamente que los factores de seguridad estaban suficientemente controlados", en AYLLÓN DÍAZ-GONZÁLEZ, J. M., Derecho..., cit., p. 37.
} 
Posteriormente, acontecimientos sucesivos como los desastres de Three Mile Island, Chernóbyl y Fukushima, han puesto de manifiesto que el desastre puede manifestarse con consecuencias devastadoras ${ }^{8}$, y que es imperiosamente necesario plantearse de forma efectiva una ponderación entre el beneficio social de la generación de energía de origen nuclear y los riesgos que esta conlleva ${ }^{9}$. En este sentido, tomo como ejemplo a Italia, país en el que en 1987 se realizó un referéndum al respecto, tras el cual se decidió abandonar la producción de energía de origen nuclear. En 2011 se ratificó esta decisión en otro referéndum celebrado en el país transalpino ${ }^{10}$.

Históricamente, la industria energética nuclear se ha considerado el paradigma de la tensión entre el progreso tecnológico y el riesgo asociado. De esta manera, hasta épocas más recientes en las que surge otra indudable consecuencia del "aparato tecnológico" humano -me refiero al efecto invernadero- con un impacto global y potencialmente destructivo, la generación energética nuclear se consideraba como el único resultado de la tecnociencia capaz de tener un efecto global, en caso de catástrofe, sobre la vida en la tierra. Paradójicamente, hoy día, para una parte de la sociedad política e intelectual incluso ecologista-, la energía nuclear se abre paso como la solución definitiva, a corto plazo al menos, para el problema del calentamiento global. De cualquier modo, es indudable que las controversias que se suscitaron en un principio siguen estando presentes hoy día, y con más fuerza si cabe tras el accidente de Fukushima en 2011.

\footnotetext{
${ }^{8}$ En efecto, a raíz de los accidentes de Three Mile Island y, sobre todo, tras el de Chernóbyl, la opinión pública tomó conciencia de que era posible un accidente con consecuencias globales y que, en cierto modo, escapaba al control humano. En palabras de Ulrich Beck: "La ganancia de poder del "progreso" técnico-económico se ve eclipsada cada vez más por la producción de riesgos. Éstos se pueden legitimar como "efectos secundarios latentes" sólo en un estadio temprano. Con su universalización, crítica pública e investigación (anti)científica, se quitan el velo de la latencia y ganan un significado nuevo y central en las discusiones sociales y políticas", en BECK, U., La sociedad..., cit., p. 19.

${ }^{9}$ Ángel Ruiz de Apodaca advierte sobre la necesaria ponderación entre riesgo y beneficio: “[...] hay que saber ponderar no ya solo los riesgos y las probabilidades de que el mismo se materialice, sino también valorar cuáles pueden ser las funestas consecuencias en caso de que ese remoto riesgo se materialice en un resultado dañoso de consecuencias catastróficas e imprevisibles. El caso de la central nuclear de Fukushima ha puesto de manifiesto que lo impensable puede acabar sucediendo. Los desastres nucleares no dejan de enseñar lecciones sobre seguridad en la operatividad de las centrales, si bien una industria como la nuclear no puede ni debe funcionar sobre la base de mejoras posteriores a cada accidente que en ellas se produzca", en RUIZ DE APODACA, A., "El marco jurídico actual de la energía nuclear en España”, Doménech Pascual, G. (coord.), El futuro de la energía nuclear en España. Perspectivas (no) sólo jurídicas, Tirant Lo Blanch, Valencia, 2013.

${ }^{10}$ MORA, M., "Los italianos rechazan la energía nuclear y la inmunidad de Berlusconi”, El País (2011, 13 de junio). Recuperado el 23 de enero de 2015, de http://internacional.elpais.com/internacional/2011/06/13/actualidad/1307916001_850215.html
} 
En este trabajo se pretende abordar los problemas de incertidumbre inherentes a la tecnología nuclear como fuente de suministro eléctrico y, a partir de aquí, analizar la aplicación del principio de precaución como instrumento jurídico para la regulación del sector. Asimismo, también se analizará la incertidumbre energética desde el punto de vista de la garantía de suministro a fin de establecer una comparativa entre el beneficio energético y el riesgo asociado. Por último, se analizarán los problemas actuales en torno a la decisión del uso de energía nuclear y la legitimad de dicha decisión.

\section{UN ACERCAMIENTO AL PRINCIPIO DE PRECAUCIÓN. LA PONDERACIÓN ENTRE RIESGO Y BENEFICIO OBTENIDO}

Tal y como afirma Anthony GIDDENS: "Riesgo — risk — no es exactamente lo mismo que peligro -danger-. El riesgo se refiere a los peligros que nos planteamos afrontar y evaluar activamente" ${ }^{\prime 1}$. Efectivamente, el riesgo conlleva una probabilidad de peligro que hemos de evaluar y cuya materialización jurídica define el principio de precaución. Dicho esto, podemos afirmar que el principio de precaución tiende a ser una de las respuestas que el sistema jurídico ha proyectado a fin de dar una solución objetiva a una valoración de riesgo proveniente de una aplicación tecnológica, cuyas probabilidades y consecuencias no han sido concretadas por las instituciones expertas. Es decir, estas probabilidades y consecuencias ${ }^{12}$ son fuente de incertidumbre y, por ello, deben ser reguladas por el ordenamiento. De esta forma, podríamos definir el principio de precaución como el instrumento que posee el poder público y el derecho para decidir en situaciones de incertidumbre científica ${ }^{13}$. En efecto, la incertidumbre es la nota definitoria de este instrumento jurídico y permite que los poderes públicos decidan ante hechos, proyectos y actividades cuyas bases científicas son "incontrovertidas"14.

\footnotetext{
${ }^{11}$ GIDDENS, A., The Third Way. The Renewal of Social Democracy, Polity Press, Cambridge, 1998.

${ }^{12}$ Algunos autores como Andy Stirling llaman "ignorancia" a las situaciones en las que no se pueden asignar ni probabilidades ni consecuencias. STIRLING, A.; RENN, O.; KLINKE, A.; RIP, A. \& SALO, A., "On science and precaution in the management of technological risk", Technological Risk and Management of Uncertainty, Report ESTO/SPRU, Sussex, 1999.

${ }^{13}$ ESTEVE PARDO, J., El desconcierto del Leviatán. Politica y derecho ante las incertidumbres de la ciencia, Marcial Pons, Madrid, 2009, p. 211.

${ }^{14}$ LAGO CANDEIRA, A. y LOZANO CUTANDA, B., "El derecho ambiental de la Unión Europea", Lozano Cutanda, B. (dir.), Tratado de derecho ambiental, CEF, Madrid, 2014. En este sentido, Blanca Mendoza Buergo afirma que "podemos considerar que hay 3 elementos presentes en todas las declaraciones del principio de precaución: que haya razones serias, basadas en datos científicos, para creer que una tecnología o actividad puede conllevar algún tipo de peligro grave de alcance colectivo,
} 
El principio de precaución fue reconocido en la Conferencia de las Naciones Unidas de Estocolmo en el año 1972 y, posteriormente, fue puesto en práctica en las políticas ambientales de la Alemania occidental - Vorsorgeprinzip ${ }^{15}$. Su importancia se refleja en la Declaración de Río de 1992, en la cual se proclama como uno de sus principios ${ }^{16}$. De cualquier modo, no fue hasta el Consejo Europeo de Niza, celebrado en el año 2000, cuando se destacó el principio de precaución como orientador de las políticas ambientales de los Estados miembros. Ahora bien, no son pocos los críticos de esta forma de actuación en la política y el derecho ambiental debido a su posibilidad de aplicación tanto como "parálisis del progreso" como inductor del "estado de excepción". Entre ellos podemos citar a dos autores de referencia en la materia como Carl SUNSTEIN y José ESTEVE PARDO. Para el primer autor, la aplicación del principio de precaución supone, en muchas ocasiones, la privación de beneficios para la sociedad que se derivan del propio progreso tecnológico, por lo que, paradójicamente, la aplicación de este daría lugar a un riesgo de paralización y supondría, a su vez, la asimilación de costes que también supondrían un riesgo ${ }^{17}$. Para José Esteve Pardo, la aplicación del principio de precaución en la política ambiental actual no hace sino resaltar la "deriva cientificista del derecho". En este sentido, el autor afirma que la aplicación del principio supone establecer medidas "de excepción”, y se deja en todo caso en manos de la ciencia la vigencia de estas medidas ${ }^{18}$.

Parece lógico que la aplicación de este principio supone una respuesta de los poderes institucionales ante situaciones cuyos procesos son completa o parcialmente

tanto para la salud de las generaciones actuales o futuras o para el medio ambiente, la fauna o la flora; que haya una falta de evidencia plena o incerteza científica respecto a la naturaleza y dimensión de tal daño y, finalmente, la necesidad y justificación ante lo anterior de tomar medidas para anticiparse y estar en condiciones de prevenir el eventual daño de carácter grave y/o irreversible", en MENDOZA BUERGO, B., "El derecho penal ante la globalización. El papel del principio de precaución", Bacigalupo, S., Derecho Penal y Política Transnacional, Atelier, Barcelona, 2005,pp. 319 a 342.

${ }^{15}$ SERRANO, J., Ciencia+tecnología + sociedad+museos $=$ cómo conseguir que el futuro se parezca a lo que esperamos, Trea, Madrid, 2013, p. 256.

${ }^{16}$ El principio 15 de la Declaración de Río de 1992 proclama: "Con el fin de proteger el medio ambiente, los Estados deberán aplicar ampliamente el criterio de precaución conforme a sus capacidades. Cuando haya peligro de daño grave o irreversible, la falta de certeza científica absoluta no deberá utilizarse como razón para postergar la adopción de medidas eficaces en función de los costos para impedir la degradación del medio ambiente". Departamento de Asuntos Económicos y Sociales - División de Desarrollo Sostenible de Naciones Unidas (1972,5 a 16 de junio). Informe de la Conferencia de las Naciones Unidas sobre el Medio Humano. Recuperado el 12 de enero 2015, de http://www.un.org/spanish/esa/sustdev/agenda21/riodeclaration.htm.

${ }^{17}$ SUNSTEIN, C. R., Leyes del miedo. Más allá del principio de precaución, Katz, Madrid, 2005, p. 306.

${ }^{18}$ Para el autor: "[...] es la ciencia y no el derecho la que abre y cierra el período de excepción que queda bajo el dominio del principio de precaución”, en ESTEVE PARDO, J., El desconcierto del..., cit., p. 147. 
desconocidos. De esta forma, se trata de ejecutar una acción a posibles situaciones de riesgo, más o menos probables, y con unas consecuencias determinadas, de manera que no es preciso tener un conocimiento cierto de la relación de causalidad entre actividad y perjuicio sino que puede aplicarse ante simples indicios de existencia de dicha relación. En base a esto, la aplicación del principio de precaución va a girar en torno a dos conceptos: la probabilidad de que el riesgo se materialice y la consecuencia de ello. Los poderes institucionales deberán ponderar los valores de probabilidad y consecuencia, así como del beneficio recibido por la sociedad en la aplicación de una determinada tecnología y, de esta forma, emitir una respuesta proporcional ${ }^{19}$ a dicha valoración. Parece claro, en cualquier caso, que se van a manejar datos suministrados por los científicos, pero la importancia radica en que el juicio de ponderación ${ }^{20}$ y la respuesta dada provengan, en última instancia, de los poderes legitimados para ello.

Efectivamente, cuando se aplica el principio de precaución se están estableciendo medidas que pueden ser de mayor o menor grado y cuyo fin es, en caso de riesgos no determinados de forma concluyente, minimizar en lo posible la probabilidad y consecuencia de que se materialicen. Es conveniente citar la Comunicación que la Comisión Europea adoptó en el año 2000 al respecto de la utilización del principio de precaución por los Estados miembros, la cual establece unas directrices por las que dicho principio deberá aplicarse "a casos en los que se han identificado riesgos potencialmente peligrosos para el medio ambiente derivados de un fenómeno, producto o proceso, pero no puede procederse a una evaluación científica detallada del nivel de

\footnotetext{
${ }^{19}$ Interesa destacar aquí, en relación con la naturaleza proporcional de la respuesta de los poderes públicos, parte de la Sentencia del TJUE sobre el caso National Farmers Unión, donde se define el principio de precaución: "El principio de precaución permite a las autoridades públicas competentes adoptar medidas preventivas proporcionadas, no discriminatorias y de carácter provisional cuando, a pesar de haberse llevado a cabo una evaluación de riesgos lo más completa posible, persiste la incertidumbre científica sobre la naturaleza y el alcance del riesgo inaceptable". Sentencia de 5 de mayo de 1998, del TJUE, sobre el caso National Farmers Unión (asunto n C-157/96).

${ }^{20}$ Para Jordi Jaria i Manzano, "se trata de determinar el equilibrio entre las supuestas compensaciones en términos de bienestar y los riesgos que una sociedad asume desde el punto de vista ambiental para obtenerlas. El principio de precaución constituye la concreción jurídica del juicio sobre el riesgo, de modo que aquellos riesgos plausibles y no asumibles socialmente, quedan bloqueados por el ordenamiento jurídico", en JARIA I MANZANO, J., La cuestión ambiental y la transformación de lo público, Tirant Lo Blanch, Valencia, 2011, p. 247. En este sentido, podemos citar también a Raúl Canosa Usera, quien, acerca de la protección del medio ambiente en el ámbito constitucional, indica que "es tarea del intérprete determinar, en cada momento, el grado de protección del medio, para que tal protección no menoscabe la debida tutela de otros intereses, también constitucionales. Se precisa una ponderación, tanto más difícil cuanto que se halla sometida a los vaivenes de las aspiraciones sociales, económicas o políticas", en CANOSA USERA, R., "Aspectos constitucionales del Derecho ambiental”, Revista de Estudios Políticos, 94, 1996, p. 80.
} 
riesgo" ${ }^{21}$.Es decir, se refiere a actividades cuyos riesgos se sabe que existen, pero cuyas probabilidades de materializarse y cuyas consecuencias suponen una fuente de incertidumbre.

Por otro lado, parece claro que el principio de precaución no establece solo que se han de tomar medidas concretas encaminadas a disminuir los niveles de probabilidad en caso de riesgos inciertos. Podemos citar también la Sentencia de 5 de mayo de 1998, conocida como National Farmers Union, en la que el Tribunal de Justicia de la Unión Europea (TJUE) consideró, sobre la base del principio de precaución, optar al "riesgo cero" al declarar que la medida de prohibición de carne de vacuno procedente del Reino Unido adoptada por la Comisión no violó el principio de proporcionalidad ${ }^{22}$. La medida adoptada en ese caso fue, directamente, la prohibición de una actividad. En este sentido, parece lógico pensar que no solo podemos "abanderar" el principio de precaución a fin de establecer medidas encaminadas a reducir el riesgo que se presupone en una actividad, sino también para prohibir las actividades cuyos riesgos, de materializarse, pudieran suponer unas consecuencias potencialmente perjudiciales para la salud y el medio ambiente ${ }^{23}$.

En cualquier caso, y como veremos más adelante, la aplicación del principio de precaución suele llevar aparejada la aparición de otros riesgos relacionados con otras alternativas o con las consecuencias sobre el bienestar social tras prohibir o tomar medidas en la aplicación de una actividad. De este modo, se hace necesario que los

\footnotetext{
${ }^{21}$ Comunicación del 2 de febrero de 2000 [COM (2000) 1 final].

${ }^{22}$ LAGO CANDEIRA, A. y LOZANO CUTANDA, B., El derecho ambiental..., cit., pp. 128 a 129.

${ }^{23}$ Autores como José Esteve Pardo critican el concepto de "riesgo cero" ya que, aunque se tienda a optar este al prohibir una determinada actividad con supuesto riesgo, la propia prohibición implicará la ausencia del beneficio que podría aportar dicha actividad, con lo cual surgiría otro riesgo derivado de la prohibición. Por ejemplo: en el caso de que se prohíba la producción energética nuclear, surgirían otros riesgos como menor seguridad en el suministro, mayor emisión de gases de efecto invernadero, etc., en ESTEVE PARDO, J., “Convivir con el riesgo. La determinación del riesgo permitido”, Arana García, E., Mercado Pacheco, P., Pérez Alonso, E., y Serrano Moreno, J. L., Derecho, Globalización y Medio Ambiente, Tirant Lo Blanch, Valencia, 2012, pp. 273 a 302.Por otro lado, y también respecto a la energía nuclear, podemos citar a José Luis Luján y Oliver Todt, que afirman lo siguiente: "Conceder un papel central al principio de precaución sería otra propuesta relevante a la hora de llevar a cabo un cambio en la forma de tratar los riesgos asociados a la producción electronuclear. Una de las formulaciones del principio propone que, ante procesos cuyas consecuencias para el entorno y los seres humanos puedan ser graves, es mejor tratar de evitar que se produzcan esas consecuencias a intervenir a posteriori, incluso si no hay prueba concluyente del daño, bastaría con la existencia de incertidumbres científicas al respecto". Para una clasificación de las formulaciones del principio de precaución, consúltese LUJÁN, J. L. y TODT, O., "Ciencia precautoria y la fabricación de incertidumbre", proyecto "El principio de precaución en la evaluación de riesgos", MEC, presentado en el V Congreso de la Sociedad de Lógica, Metodología y Filosofía de la Ciencia en España, Granada, 2006.
} 
poderes públicos realicen un análisis prospectivo a fin de ponderar adecuadamente los niveles de riesgo con los beneficios de la aplicación de una determinada tecnología ${ }^{24}$.

III. LA INCERTIDUMBRE EN LA VALORACIÓN DE LOS RIESGOS ASOCIADOS A LA GENERACIÓN DE ELECTRICIDAD DE ORIGEN NUCLEAR. LA APLICACIÓN DEL PRINCIPIO DE PRECAUCIÓN EN EL SECTOR

Para el análisis de la aplicación del principio de precaución en la industria energética nuclear es necesario formular previamente las dos variables a ponderar: el nivel de riesgo y el beneficio. Cabe preguntarse, principalmente, dos cuestiones: ¿qué nivel de riesgo estamos dispuestos a asumir? y ¿se compensa dicho nivel de riesgo con el beneficio obtenido?

Respecto a la primera cuestión, debemos considerar dos magnitudes para valorar el riesgo: la probabilidad de materialización de este y las consecuencias asociadas ${ }^{25}$. Y he aquí donde surgen las principales incertidumbres ${ }^{26}$ de la tecnología nuclear: ¿qué probabilidad existe de que suceda un accidente nuclear con emisión de radiación? y ¿qué consecuencias tendría la materialización de un accidente nuclear grave? Desgraciadamente, respecto a esta segunda cuestión ya tenemos algunas respuestas empíricas debido a los mencionados accidentes de Chernóbyl y Fukushima, pero, aun así, estas experiencias han demostrado también que las estimaciones de riesgo no han sido precisas y que las consecuencias, de producirse el accidente, pueden ser incalculables en términos de daños a la salud, al medio ambiente y, por supuesto, a la economía.

\footnotetext{
${ }^{24}$ Efectivamente, la posibilidad de que una tecnología no se utilice debido a una aplicación del principio de precaución puede suponer la aparición de alternativas con mayores niveles de riesgo asociado. Igualmente, ha de valorarse el beneficio que producirá dicha tecnología a la sociedad, aun con sus riesgos intrínsecos - por ejemplo: la utilización de transgénicos para mejorar la productividad en países del Tercer Mundo-.

${ }^{25}$ Para una lectura sobre la valoración del riesgo en la industria energética nuclear y su problemática, vid. BENACH, J., CIRERA, A., y RODRÍGUEZ FARRÉ, ¿Átomos de fiar? Impacto de la energía nuclear sobre la salud y el medio ambiente, Catarata, Madrid, 2007. Sobre el mismo tema: MEYER-ABICH, K. M., "Von der Wohlstandsgesellschaft zur Risikogesellschaft", Aus Politik und Zeitgeschichte, vol. 36, 1989 , pp. 31 y 32 .

${ }^{26}$ Es necesario diferenciar aquí entre situaciones de riesgo y de incertidumbre. En el caso de la energía nuclear, al desconocerse en cierto modo las probabilidades y las consecuencias de un accidente, se tiende a tomar como una tecnología que genera incertidumbre. Consúltese al respecto: STIRLING, A.; RENN, O.; KLINKE, A.; RIP, A. \& SALO, A., On science..., cit.
} 
En cualquier caso, es lógico pensar que la posibilidad de un accidente grave es altamente improbable, más aún teniendo en cuenta que tras los accidentes mencionados se ha podido indagar en profundidad sobre aspectos de mejora en la seguridad de las instalaciones. Pero también es necesario resaltar la poca fiabilidad que ha demostrado, en alguna ocasión, el sistema de gestión de riesgos por parte de los expertos -incluso en épocas recientes-. En relación con esto, cabe mencionar que, tras la catástrofe de Fukushima, la empresa gestora de la central nuclear -la empresa TEPCO- admitió que "minimizó" las posibilidades de que un tsunami pudiera dañar sus instalaciones ${ }^{27}$. Parece claro que, en un asunto como el que concierne a la energía nuclear, no podemos permitirnos abordar metodologías de ensayo-error ya que un fallo puede suponer una situación de desastre ambiental y humano de consecuencias irreversibles. En cualquier caso, si damos por válido el argumento del aumento de seguridad en las centrales nucleares que están en funcionamiento hoy día todavía nos quedan dos asuntos a tratar en cuanto a los riesgos asociados a la tecnología nuclear: los residuos nucleares y la proliferación de armamento nuclear.

Respecto a los residuos, puede decirse que son, junto con la seguridad, el principal quebradero de cabeza de las instituciones de la energía atómica tanto nacionales como internacionales y que, a día de hoy, la solución para su almacenamiento permanente y efectivo sigue siendo una incógnita a solucionar por estas instituciones y los Estados implicados. En relación con la proliferación de armamento nuclear, el debate nace porque la tecnología utilizada en el enriquecimiento de uranio para su uso pacífíco puede funcionar también para la construcción de armamento nuclear. Además, el plutonio producido en las centrales nucleares también puede usarse para bombas atómicas.

Por otro lado, resulta evidente que la utilización de tecnología nuclear para la generación de energía eléctrica supone un riesgo que, de materializarse en su naturaleza más destructiva, resultaría de consecuencias catastróficas. Nunca un accidente ambiental causó tantos desplazamientos humanos ${ }^{28}$ ni tanta incertidumbre respecto a sus consecuencias futuras para los residentes en áreas cercanas y afectados -casos de

\footnotetext{
${ }^{27}$ COLPISA, "TEPCO admite que minimizó el riesgo de tsunami en Fukushima”, Diario Vasco (2012, 12 de octubre). Recuperado el 24 de enero de 2015, de http://www.diariovasco.com/rc/20121012/masactualidad/internacional/tepco-admite-haber-minimizado-201210122126.html

${ }^{28}$ Para un análisis en profundidad del problema de los refugiados ambientales, consúltese BORRÀS PENTINAT, S., "Refugiados ambientales. El nuevo desafío del derecho internacional del medio ambiente", Revista de Derecho, vol. 19, núm. 2, 2006, pp. 85 a 108.
} 
cáncer- ni el impacto en la habitabilidad de una zona ha sido tan profunda como la catástrofe de Chernóbyl — se estima que pasarán miles de años hasta que se pueda vivir de nuevo en los $30.000 \mathrm{~km}^{2}$ alrededor de la central ${ }^{29}$. Y, aunque es evidente que fueron errores humanos los "catalizadores" del accidente del generador ucraniano, en Fukushima fue la propia naturaleza la que desencadenó el accidente independientemente de que la previsión humana pudiera haber limitado o evitado el desastre. El resultado es de sobra conocido: áreas contaminadas cuya habitabilidad no se recuperará hasta miles de años después, aumento de la mortalidad por cánceres en poblaciones afectadas por la nube radiactiva y en sujetos directa o indirectamente expuestos, así como desarrollo de malformaciones en las generaciones venideras relacionadas con dichas poblaciones.

En definitiva, existen importantes fuentes de incertidumbre en la tecnología energética nuclear que, sin duda, deben ser afrontadas por los Estados que utilicen dicha tecnología a fin de darles soluciones definitivas. En relación con esto, es necesario mencionar el informe que el Massachusetts Institute of Technology (MIT) emitió en el 2003 sobre el futuro de la energía nuclear, donde se afirmaba que "si se quería mantener la opción energética nuclear, sería preciso hacer frente a 4 problemas: coste, seguridad, residuos y proliferación" $" 30$. Sobre la base de este informe, se analizarán en los próximos apartados dichos problemas como fuentes de incertidumbre de la energía nuclear.

\section{La incertidumbre en cuanto a la seguridad de las instalaciones nucleares}

Para Charles PERROW, los accidentes en sistemas tecnológicos complejos son inevitables debido a la cantidad de subsistemas que los componen, ya que, en caso de error en cualquiera de ellos, podría darse una acumulación de fallos de forma exponencial. Por ello, resultan impredecibles para los propios expertos ${ }^{31}$.

Por supuesto, a nadie se le escapa que una instalación energética nuclear debe ser un sistema tecnológico de gran complejidad, por lo que el derecho suele limitarse a

\footnotetext{
${ }^{29}$ ANSPAUGH, L., CATLIN, R y GOLDMAN, M., "The Global Impact of the Chernobyl reactor accident", Science, vol. 242, diciembre de 1988.

${ }^{30}$ Informe Massachusetts Institute of Technology (2003), "The future of Nuclear Power". Recuperado el 13 de enero de 2014, de http://web.mit.edu/nuclearpower/

${ }^{31}$ Charles Perrow habla de los "accidentes normales" como aquellos que son inherentes a los propios sistemas tecnológicos complejos. En este sentido, vid. PERROW, C., Normal Accidents: Living with High Risk Technologies, Basic Books, Nueva York, 1984.
} 
establecer cláusulas de "mejora tecnológica" o de "máxima seguridad" según el state of art, confiando siempre en la capacidad experta para afrontar esos niveles de riesgo ${ }^{32}$. En este sentido, la actuación del derecho en cuanto a las cláusulas mencionadas se presenta lógica ya que se ve sobrepasado por el nivel tecnológico y científico, y, consecuentemente, tendrá difícil dar una valoración de riesgo acertada o unos criterios específicos para el correcto funcionamiento de una instalación nuclear. Además, si tenemos en cuenta que el progreso tecnológico implicará un aumento de seguridad en las instalaciones nucleares, los criterios que establecería el derecho serían mucho más contraproducentes que efectivos debido a que la normativa jurídica presenta un mayor grado de inamovilidad que la evolución tecnológica. Por ello, en este ámbito, debe depender necesariamente de los dictámenes expertos ${ }^{33}$. Por supuesto, el análisis tecnológico de las instalaciones nucleares y la seguridad de sus procesos se escapa a los fundamentos de este trabajo, por lo que afrontaré el problema desde las perspectivas sobre las que el derecho sí que puede - y debe - actuar: el emplazamiento de las instalaciones, la protección radiológica ${ }^{34}$, la protección contra ataques terroristas y la vida útil de la instalación.

Es indudable que la gestión del emplazamiento de una instalación nuclear ${ }^{35}$ es la fase en la que la aplicación del principio de precaución como "minimizador" del riesgo - y no como fundamentación del riesgo cero - tiene una mayor trascendencia. El desastre nuclear de Fukushima evidencia este hecho, aunque se quiera ocultar de alguna forma con la consabida fórmula de que "no se tomaron las medidas preventivas adecuadas". La incertidumbre opera sobre este factor dado que no podemos prever ni controlar todos los peligros naturales. Podemos adelantar cuándo va a suceder un terremoto y cuándo se desarrollará un tsunami, pero no tenemos margen de tiempo ni de error para superarlos. La instalación de una central nuclear en una zona estable geológicamente es una medida

\footnotetext{
${ }^{32}$ Es por ello por lo que existe en España la Comisión de Seguridad Nuclear -en adelante, CSN-, que es el organismo encargado de la seguridad de las instalaciones nucleares.

${ }^{33} \mathrm{Si}$ el derecho no valora esta opción, parece claro que la única posibilidad respecto del tratamiento jurídico del funcionamiento de una central nuclear sería la del "riesgo cero", es decir, la supresión de la actividad.

${ }^{34}$ Juan Manuel Ayllón distingue entre la seguridad nuclear y la protección radiológica. De esta forma, afirma que con la seguridad nuclear lo que se intenta es evitar el funcionamiento anormal de las instalaciones nucleares -accidentes-, mientras que, con la protección radiológica el daño en las personas y el medio ambiente. AYLLÓN DÍAZ-GONZÁLEZ, J. M., Derecho..., cit., pp. 517 a 519.

${ }^{35}$ Se entiende que se hace referencia solo a centrales de generación de energía y almacenes temporales centralizados (ATC).
} 
preventiva y necesaria, pero -y he aquí otro problema heredado de la época del "furor nuclear"- en las centrales construidas en España en las décadas de 1960 y 1970 no se tomaron en cuenta criterios, normativas y regulaciones de carácter "independiente" en este sentido, ya que la Ley del Centro de Seguridad Nuclear, con sus importantes previsiones al respecto, se aprobó en $1980^{36}$.

Actualmente, es necesario el informe - preceptivo y vinculante- del CSN para el emplazamiento de las instalaciones nucleares que contemplen dicha autorización ${ }^{37}$. Además, y debido en gran parte al rechazo social que se aprecia en todo lo relacionado con una instalación de este tipo, se hace indispensable para las instituciones públicas que las poblaciones que "acojan" estas infraestructuras sean conscientes del riesgo y acepten de buen grado, ya sea por un beneficio colateral -por ejemplo, puestos de trabajo- o por cualquier otro motivo, la construcción de esta. Tanto es así que, para la construcción del Almacén Temporal Centralizado -en adelante, ATC- de Villar de Cañas (Cuenca), se tuvieron que poner en marcha un conjunto de candidaturas, de las cuales, en principio, se ha evaluado la más óptima ${ }^{38}$. Aunque es sorprendente el hecho de que, a día de hoy, el informe del CSN no haya sido emitido y que, en su momento, la Comisión interministerial encargada de la valoración de las candidaturas emitiera un juicio de carácter técnico sobre la ubicación ${ }^{39}$. Es lógico pensar que el Gobierno, con el trámite de convocatoria pública para el emplazamiento del ATC, ha cumplido parte de la valoración sociopolítica en la elección final, pero es necesario preguntarse qué

\footnotetext{
${ }^{36}$ En este sentido, vid. ALLENDE LANDA, J., "Política de ubicación de Centrales Nucleares en España”, Estudios Territoriales, núm. 17, enero de 1985, pp. 195 a 207. En cuanto a esta cuestión, Juan Manuel Ayllón afirma que "las importantes previsiones recogidas al respecto en la LCSN no han sido aplicadas hasta el momento a ninguna instalación y es muy posible que no lo sean una vez que se ha puesto coto a la construcción de nuevas centrales y las instalaciones de almacenamiento siguen quedando inexplicablemente exentas del requisito de la prevista", en AYLLÓN DÍAZ-GONZÁLEZ, J. M., Derecho..., cit., p. 400. Respecto a la instalación del ATC, hemos de mencionar el Real Decreto $775 / 2006$, de 23 de junio, por el que se crea la Comisión interministerial para el establecimiento de los criterios que deberá cumplir el emplazamiento del almacén temporal centralizado de combustible nuclear gastado y residuos de alta actividad, y de su centro tecnológico asociado.

${ }^{37}$ Un exhaustivo trabajo sobre el régimen de autorizaciones de las instalaciones nucleares en España lo encontramos en la obra de BARCELÓ, A., Instalaciones nucleares. Autorización y conflicto, Ariel, Barcelona, 2002.

${ }^{38}$ PLANELLES, M. y SEVILLANO, E. G., "El silo nuclear de Cuenca avanza pese a las dudas sobre el terreno", El País (2014, 17 de diciembre). Recuperado el 14 de enero de 2015, de http://politica.elpais.com/politica/2014/12/17/actualidad/1418843415_760400.html

${ }^{39}$ Resolución de 18 de enero de 2012, de la Secretaría de Estado de Energía, por la que se publica el Acuerdo de Consejo de Ministros de 30 de diciembre de 2011, por el que se aprueba la designación del emplazamiento del Almacén Temporal Centralizado de combustible nuclear gastado y residuos de alta actividad y su Centro Tecnológico Asociado.
} 
sucederá con el emplazamiento del tan ansiado ATC si, finalmente, los informes técnicos del CSN no son favorables ${ }^{40}$.

De cualquier modo, cuesta entender que en la normativa de referencia no haya ningún criterio concreto respecto del emplazamiento, siendo una autorización de tal importancia dados los parámetros sociales, económicos y de seguridad, y que se deje en manos de los expertos la valoración de dichos criterios. Se trata de un ejemplo claro de, en palabras de José ESTEVE PARDO, "deriva cientificista" del derecho sobre la base del principio de precaución ${ }^{41}$.

Respecto a la protección radiológica, es necesario advertir que me refiero aquí al ámbito concreto del sector energético nuclear ${ }^{42}$, y no al ámbito médico —en el cual podemos valorar otras consideraciones éticas, individuales, científicas, etc. La protección radiológica, en este sentido, es un ejemplo paradigmático de incertidumbre científica, en este caso en cuanto a los efectos estocásticos — se denomina así a los efectos cuya probabilidad de darse dependen de la dosis recibida - de la radiación. Menciónese que hasta la década de 1950 los científicos daban por hecho que, sin superar unas dosis determinadas, la radiación era totalmente inocua. Hoy día se sabe que no es así y, aunque se han establecido dosis máximas en la normativa reguladora, estos valores se basan en establecer "la frontera más baja de la región de las dosis inaceptables". Las dosis actualmente admisibles se recogen, en España, en el Real Decreto 783/2001, de 6 de julio, por el que se aprueba el Reglamento sobre protección sanitaria sobre radiaciones ionizantes —en adelante, RPSRI. Este reglamento es fruto de la transposición de la Directiva 96/29/Euratom ${ }^{43}$, que, a su vez, se basa en los criterios de la Comisión Internacional de Protección Radiológica —en adelante, CIPR. El CIPR es una entidad de carácter privado e independiente formada por expertos en protección

\footnotetext{
${ }^{40}$ Una profunda reflexión sobre el procedimiento de elección del emplazamiento la encontramos en RUIZ DE APODACA, A., "El marco jurídico...", cit.

${ }^{41}$ ESTEVE PARDO, J., El desconcierto del..., cit., p. 141.

${ }^{42}$ Para un análisis exhaustivo del impacto radiológico de la energía nuclear, vid. BENACH, J., CIRERA, A. y RODRÍGUEZ FARRÉ, ¿Átomos de fiar?..., cit.

${ }^{43}$ Hay que señalar que esta directiva ha sido derogada por el artículo 107 de la Directiva 2013/59/Euratom del Consejo, de 5 de diciembre de 2013, por la que se establecen normas de seguridad básicas para la protección contra los peligros derivados de la exposición a radiaciones ionizantes, y se derogan las Directivas 89/618/Euratom, 90/641/Euratom, 96/29/Euratom, 97/43/Euratom y 2003/122/Euratom.
} 
radiológica, que establecen criterios de protección que, a la postre, son tomados en consideración por la mayoría de Estados ${ }^{44}$.

Ahora bien, tal y como hemos mencionado, no se ha podido establecer una dosis umbral cuyos efectos estocásticos no supongan un riesgo de contraer cáncer. A este respecto, de lo que se trata es de establecer las medidas más restrictivas posibles a fin de mantener las dosis en valores "razonables" ${ }^{4}$. Cabe mencionar en este sentido que el artículo 2 del RPSRI establece: "Las dosis individuales, el número de personas expuestas y la probabilidad de que se produzcan exposiciones potenciales, deberán mantenerse en el valor más bajo que sea razonablemente posible, teniendo en cuenta factores económicos y sociales".

Así, entrando a valorar ahora la cuestión social, como afirma Leopoldo ARRANZ:

La CIPR basa sus principios en limitar las dosis a unos niveles de riesgo “aceptables". Sin embargo, la gestión de una situación o de una actividad de riesgo aceptable no ha suscitado entre la población la adhesión esperada. El riesgo no tiene el mismo sentido para todos y su "aceptabilidad" dependerá del contexto de la situación considerada ${ }^{46}$ [las comillas son del autor].

Efectivamente, se deja entrever que es necesario tener en cuenta la valoración del público a la hora de aceptar la posibilidad de someterse a niveles de radiación, aunque sean "científicamente tolerables", ya que es una situación que no está sometida a elección individual. Puedo elegir comprar vegetales de cultivo ecológico y no transgénico, pero no puedo escoger estar expuesto a los riesgos de un tipo u otro de energía si el Estado ya ha definido la política energética ${ }^{47}$.

Pero no todos los riesgos asociados a la industria tecnológica nuclear son riesgos naturales o intrínsecos a la propia tecnología, sino que también podemos considerar un grupo de riesgos antrópicos como los actos de terrorismo — además del ya mencionado

\footnotetext{
${ }^{44}$ AYLLÓN DÍAZ-GONZÁLEZ, J. M., Derecho..., cit., pp. 571 a 572.

${ }^{45}$ Tal y como advierten Joan Benach et ál.: "Los efectos sobre la salud y el medio ambiente producidos por las radiaciones ionizantes de las centrales nucleares y el conjunto de la actividad industrial nuclear son de muy compleja evaluación científica debido, entre otras razones, a la dificultad de estudiar su incorporación en las cadenas tróficas, la reconstrucción de las dosis de exposición de las poblaciones objeto de estudio, así como a la variedad de las respuestas biológicas que se producen". BENACH, J., CIRERA, A. y RODRÍGUEZ FARRÉ, E., ¿Átomos de fiar? ..., cit., p. 125.

${ }^{46}$ ARRANZ, L. y DE ALBORNOZ, C., "Utilización de la energía nuclear: la percepción del riesgo radiológico del público", Revista de Salud Ambiental, núm. 10 (1-2), 2010, pp. 53-56.

${ }^{47}$ Una crítica ético-social sobre la política de protección radiológica la tenemos en la obra de SHRADERFRECHETTE K.S., Energía..., cit.
} 
problema de la proliferación. Como es lógico, a nadie se le escapa que un ataque contra este tipo de instalaciones podría dejar pequeños incluso a los del 11 de septiembre de 2001 en Nueva York. En este sentido, hay que mencionar que en España se aprobaron hace unos años la Ley 8/2011, de 28 de abril, de infraestructuras críticas, la cual transpone la Directiva 2008/114, del Consejo, de 8 de diciembre, sobre la identificación y designación de infraestructuras críticas europeas y la evaluación de la necesidad de mejorar su protección; y su reglamento de desarrollo en el ámbito de las instalaciones nucleares y radiactivas: el Real Decreto 1308/2011, de 26 de septiembre, sobre protección física de las instalaciones y los materiales nucleares, y de las fuentes radiactivas $^{48}$. Toda esta normativa está encaminada a la mayor protección posible de dichas instalaciones frente a cualquier amenaza (incluida la terrorista). Por supuesto, y como no puede ser de otra forma, el hecho de que el poder destructivo de la tecnología nuclear pudiera caer en manos de personas cuyo fin sea atentar contra poblaciones humanas a fin de propagar el terror, crea una fuente de incertidumbre y miedo en la sociedad que afecta en gran medida a la aceptabilidad de las instalaciones energéticas nucleares.

Por último, y en lo que respecta a la "vida útil" de las centrales nucleares, es necesario resaltar que no hay que confundirla con la "vida de diseño", la cual se refiere a la duración mínima considerada acorde con la magnitud de la inversión planificada y durante la que se esperan conseguir los objetivos planificados. Como "vida útil" se entiende "el tiempo efectivo que transcurre desde su entrada en servicio hasta que se pueda demostrar que tiene capacidad para cumplir todas sus funciones de seguridad con el nivel de calidad requerido" ${ }^{49}$.Es decir, el concepto de vida útil está enfocado a definir las condiciones en las que una instalación nuclear puede operar en condiciones seguras, lo que será valorado por las figuras de inspección del CSN. Pues bien, respecto de todo esto, es lógico pensar que el envejecimiento de una central nuclear, con todo un sistema

\footnotetext{
${ }^{48}$ Podemos encontrar un análisis de esta normativa en RUIZ DE APODACA, A. M., "Nuevas perspectivas del Derecho Nuclear en Europa y en España", Revista electrónica del Departamento de Derecho de la Universidad de La Rioja, núm. 9, 2011, pp. 67 a 98.

${ }^{49}$ MELLADO JIMÉNEZ, I., "Renovación de las autorizaciones de explotación de las centrales nucleares", Doménech Pascual, G. (coord.), El futuro de la energía nuclear en España. Perspectivas (no) sólo jurídicas, Tirant Lo Blanch, Valencia, 2013, pp. 59-68. El CSN define vida útil como: "Vida útil (o de servicio): es el período de tiempo desde su puesta en funcionamiento hasta su retirada de servicio. La vida útil puede ser mayor que la vida de diseño, siempre que las condiciones reales de operación hayan sido menos severas que las supuestas en el diseño". Instrucción IS-22, de 1 de julio de 2009, del Consejo de Seguridad Nuclear, sobre requisitos de seguridad para la gestión del envejecimiento y la operación a largo plazo de centrales nucleares.
} 
complejo de estructura, maquinaria y procesos, puede suponer un reto en cuanto a "descifrar" cuáles son las partes obsoletas o desgastadas que deben ser reemplazadas. Todo ello unido al hecho de que el poder corrosivo, de desgaste, etc., debido a los procesos nucleares que tienen lugar en estas instalaciones se supone en gran medida solo por cálculos teóricos ${ }^{50}$. Por supuesto, volvemos a confiar en el buen hacer de nuestras instituciones expertas, pero es necesario resaltar que, sin duda, plantea otra fuente de incertidumbre para la cual el derecho sí que debe reafirmarse en una decisión concreta a fin de no dejar únicamente en manos de las herramientas planificadoras y de los expertos los términos de la vida útil de las centrales nucleares.

\section{La incertidumbre respecto a la gestión de los residuos nucleares. La afectación a las generaciones futuras.}

Sobre los residuos radiactivos, debemos hacer una primera reflexión preguntándonos si es ético manejar una tecnología cuyos residuos generados somos incapaces de gestionar hoy día ${ }^{51}$. No se trata solo de manejar sustancias con una peligrosidad evidente, sino también de considerar que, en estos momentos, el tratamiento definitivo de estas no existe. Tanto es así que, actualmente, la estrategia es el almacenamiento en un ATC como solución a los ATI -almacén temporal individual- que ya suponían un problema para las centrales puesto que, hasta ahora, debían acumular su combustible gastado en piscinas construidas al efecto, con problemas graves de espacio en muchos $\operatorname{casos}^{52}$.

El problema de los residuos ${ }^{53}$ va más allá de una simple valoración sobre el riesgo actual que pueden acarrear, ya que nos encontramos con sustancias cuyo potencial contaminante se mide en torno a miles de años ${ }^{54}$. Por ello, no solo se ha de valorar la

\footnotetext{
${ }^{50}$ Para un análisis más en profundidad de esta cuestión, vid. NOVAK, S. y PODEST, M., "Envejecimiento y prolongación de la vida útil de las centrales nucleares: aspectos de seguridad", Visión general de las cuestiones pertinentes y celebración del simposio del OIEA, 1987.

${ }^{51}$ COSTA MORATA, P. y BAÑOS PÁEZ, P., "Sociología e ideología de los residuos radiactivos: la sociedad contra la técnica", Argumentos de Razón Técnica, núm. 13, 2010, pp. 137-158.

${ }^{52}$ VÉLEZ, A. M., "Vandellós II también estudia construir otro mnialmacén nuclear por el posible retraso del ATC, Voz Pópuli (2014, 8 de julio). Recuperado el 20 de enero de 2015, de http://vozpopuli.com/economia-y-finanzas/46128-vandellos-ii-tambien-estudia-construir-otro minialmacen-nuclear-por-el-posible-retraso-del-atc

${ }^{53}$ Cabe recordar aquí la frase del senador estadounidense Howard H. Baker (1973): "la contención y almacenamiento de los residuos radiactivos es la mayor responsabilidad que haya tomado nunca conscientemente el hombre".

${ }^{54}$ En palabras de ULRICH BECK: "La energía atómica es, en este sentido, un juego, lleno de los más graves riesgos, con la supuesta "infabilidad" del desarrollo tecnológico. Genera restricciones tras
} 
afectación a nuestra sociedad, sino que también debemos tener en cuenta los derechos de las generaciones futuras ${ }^{55}$. No podemos confiar en que sean nuestros descendientes quienes afronten un problema que, claramente, es responsabilidad solo nuestra. En este sentido, no existe una tecnología cuyo potencial de afectación futuro sea mayor que la nuclear, y ello es debido a la generación de unos residuos radiactivos de alta actividad para los que, actualmente, no existe ningún sistema de gestión definitivo.

Para finalizar sobre este asunto, es necesario exponer la necesidad legislativa de una protección efectiva de las generaciones futuras. Cabe mencionar al respecto que en Alemania esta cuestión ya fue incorporada en su Ley Fundamental ${ }^{56}$. Así, el artículo 20 de la Ley Fundamental de la República Federal de Alemania establece lo siguiente: "El Estado protegerá, teniendo en cuenta también su responsabilidad con las generaciones futuras, dentro del marco constitucional, los fundamentos naturales de la vida y los animales a través de la legislación y, de acuerdo con la Ley y el Derecho, por medio de los poderes ejecutivo y judicial”.

En España, la protección de las generaciones futuras se encuadra dentro de las políticas de protección del medio ambiente, sin que haya un verdadero derecho de protección para dichas generaciones. Por supuesto, no podemos "depender" de la capacidad de resolución de las generaciones futuras para resolver nuestros problemas actuales. A nadie se le escapa que toda opción que conlleve ignorancia en cuanto a su gestión futura es irresponsable y nada ética ${ }^{57}$.

restricciones que apenas si resultan revisables y sólo limitadamente permiten aprender. Condicionan a los hombres (por ejemplo, en el aspecto de resolver el almacenaje de los residuos radiactivos) durante varias generaciones, es decir durante períodos para los cuales ni tan siquiera es posible garantizar la identidad de significado para las palabras claves", BECK, U., La Sociedad ..., cit., p. 232.

${ }^{55}$ En este sentido, Hans Jonas señalaba que el ser humano debe actuar de forma compatible con la vida indefinida en la tierra, en JONAS, H., El principio de responsabilidad: ensayo de una ética para la civilización tecnológica, Herder, Barcelona, 1995.

${ }^{56}$ HÄBERLE, P., "Un derecho constitucional para las futuras generaciones. La otra forma del contrato social: el contrato generacional”, Lecciones y Ensayos, núm. 87, 2009, pp. 17-37.

${ }^{57}$ Para Ángel Ruiz de Apodaca: "El creer que el desarrollo científico en un futuro solucionará la gestión de residuos nucleares sin tener esa certeza de ninguna manera en el presente no puede condicionar una decisión política en sentido favorable, de actuar así estaríamos ante una posición de claro antropocentrismo tecnocrático y de radical insolidaridad con las generaciones venideras", RUIZ DE APODACA, A., "El marco jurídico...", cit. 


\section{El problema de la proliferación armamentística nuclear}

Cuando hablamos de proliferación nuclear, nos referimos a la posibilidad de que países reconocidos como Estados sin armamento nuclear ${ }^{58}$-según el Tratado de No Proliferación de 1968 (en adelante, TNP) ${ }^{59}$ - obtengan tecnología y/o material para fabricar armas nucleares y tengan la intención de fabricarlas. En el caso de este tipo de proliferación, hablaríamos de una proliferación horizontal. La proliferación vertical se daría en Estados que cuentan con arsenal nuclear según el TNP, y que siguen aumentando o renovando dicho arsenal ${ }^{60}$.

La situación actual es que países como Israel, la India y Pakistán se encuentran al margen del TNP, y cuentan con armamento nuclear. En otros casos, países como Irán y Corea del Norte — que revocó su firma del Tratado en 2003-, se han declarado "hostiles" a las limitaciones que impone el $\mathrm{TNP}^{61}$. Todo esto cataliza, al generarse un dilema sobre su seguridad, una situación de proliferación en otros Estados no aliados de los anteriores.

En este caso, la fuente de incertidumbre no se deriva del propio funcionamiento de una central nuclear — como la seguridad del reactor o los residuos-, sino de la posibilidad de que los propios humanos usen dicha tecnología para desarrollar armas que, en caso de llegar a usarse, podrían poner en peligro incluso la propia vida en la tierra. Efectivamente, la tecnología de enriquecimiento de uranio para el funcionamiento de las centrales podría usarse también para obtener uranio altamente enriquecido (UAE) que serviría para la fabricación de armas nucleares. Asimismo, el plutonio, subproducto de la fisión nuclear en los reactores, puede ser utilizado también para la fabricación de

\footnotetext{
${ }^{58}$ Es interesante la reflexión que realiza Juan Manuel Ayllón respecto de las consideraciones del TNP: "Lo primero que llama la atención del Tratado de No Proliferación es que sean los Estados Proliferantes los que auspicien un Tratado de No Proliferación”. AYLLÓN DÍAZ-GONZÁLEZ, J. M., Derecho..., cit., p. 30 .

${ }^{59}$ En relación con el Estado español, la adhesión se produjo mediante el Instrumento de 13 de diciembre de 1987, de Adhesión de España al Tratado sobre la no proliferación de las armas nucleares, hecho en Londres, Moscú y Washington el 1 de julio de 1968. BOE., Boletín Oficial del Estado, núm. 313, 31 de diciembre de 1987.

${ }^{60}$ MARTÍNEZ NEGRETE, M. A., "La carrera armamentista nuclear en el umbral del siglo XXI", Revista Ciencias - Universidad Autónoma de México, núm. 33, enero-marzo, 1994.

${ }^{61}$ FERNÁNDEZ-SOLA, N., "Una respuesta multilateral a la proliferación nuclear: las perspectivas de la conferencia de revisión de 2010 del Tratado de No Proliferación Nuclear", Anuario de derecho internacional $X X V$, Servicio de Publicaciones de la Universidad de Navarra, pp. 319 a 345.
} 
dicho armamento ${ }^{62}$. Todo esto implica que los países con tecnología energética nuclear sean también capaces de usarla para construir bombas nucleares, lo que supone un problema de enormes dimensiones que se debe resolver si se opta por un futuro energético donde lo nuclear tenga cabida. El hecho de que países en tensión permanente, ya sean países con o sin armamento nuclear según el TNP, cuenten de forma efectiva con esa capacidad de destrucción genera un clima de inseguridad continuo en la sociedad mundial. La desconfianza hacia el "vecino" o el enemigo es lo que nutre esta posesión, por lo que es necesario establecer vínculos de cooperación entre unos y otros para, y debe ser el fin mismo, completar un efectivo desarme de todos los Estados implicados.

Si queremos que la energía nuclear desempeñe un importante papel en el futuro energético mundial, es crucial y necesario abordar con todas las fuerzas posibles el problema de la proliferación de armamento nuclear, todo ello en colaboración con las potencias poseedoras e implicadas en la utilización de esta tecnología para la fabricación de armamento atómico. No es necesario mencionar los efectos globales que solo un accidente podría acarrear, sino que con más fuerza se producirían en caso de estallar una guerra atómica entre potencias enfrentadas.

\section{El coste de la generación energética nuclear}

Dejando a un lado el coste de construcción y funcionamiento normal de una central nuclear, lo cual puede ser calculado a partir de los parámetros funcionales y legales de la actualidad, lo que nos interesa valorar son los costes relacionados con el funcionamiento anormal de una central nuclear y los costes relacionados con la gestión de los residuos, ya que estos están relacionados con las situaciones de incertidumbre que se comentaron en apartados anteriores. Además, hay que señalar que el riesgo de que se establezcan legalmente nuevas especificaciones técnicas de seguridad, que serían obligatorias para las empresas gestoras de centrales nucleares, es muy alto ${ }^{63}$ con el

\footnotetext{
${ }^{62}$ Una reflexión sobre ello la tenemos en LÓPEZ ARNAL, S. y RODRÍGUEZ FARRÉ, Casi todo lo que usted desea saber sobre los efectos de la energía nuclear en la salud y el medio ambiente, Ediciones El Viejo Topo, España, 2008, pp. 40 a 41.

${ }^{63}$ En este sentido, Cayetano Espejo Marín afirma "Las empresas eléctricas españolas no apuestan por la construcción de nuevas centrales nucleares porque su riesgo regulatorio es más elevado que el de una central térmica, hidroeléctrica o de otras energías renovables. Además son mucho mayores los costes financieros y estructurales. A ello hay que unir una razón de carácter tecnológico que actúa como barrera para la energía nuclear: no está resuelto el problema de la gestión del combustible gastado", en ESPEJO
} 
coste suplementario que supondrían-, lo que implica que las empresas eléctricas, en este caso en España, sean reacias a la construcción de nuevas centrales de este tipo.

Sin entrar tampoco a valorar el coste de generación de una unidad energética de origen nuclear y relacionarlo con el coste de otras energías, lo que queremos en este apartado es evaluar los costes económicos derivados de los problemas de incertidumbre de una instalación energética nuclear. En este sentido, y poniéndonos en la peor posición posible, es necesario abordar primero el coste de un supuesto accidente nuclear con emisión de radiación al exterior, el cual, tomando como ejemplo el último accidente nuclear de Fukushima, supondría una carga imposible de ser costeada por una entidad privada $^{64}$. Respecto a estudios realizados sobre un hipotético accidente en Europa, destaca el del Instituto para la Protección Radiológica y la Seguridad Nuclear (IRSN) de Francia $^{65}$ —en España no se ha elaborado ningún estudio oficial al respecto.Pues bien, este estudio llega a la conclusión de que un accidente severo -6 en la Escala Internacional de Eventos Nucleares, INES - en un reactor de 900 MW conllevaría unos costes de entre 40.000 y 205.000 millones de euros, mientras que un accidente grave -7 en el INES-, entre 300.000 y 5.800000 millones de euros.

A todo esto, y entrando ya en el plano jurídico, según la nueva Ley 12/2011, de 27 de mayo, sobre responsabilidad civil por daños nucleares, los titulares de instalaciones nucleares son obligados a tener cobertura de responsabilidad civil hasta 1.200 millones de euros. Según la misma normativa, el Estado asegurará un margen de hasta los 1.500 millones de euros en caso de que los daños superen los 1.200 millones. Es interesante destacar al respecto las siguientes palabras de Ángel RUIZDE APODACA:

Si un accidente nuclear supera en daños los $1500 \mathrm{M} €$, ¿Quién respondería? Pues seguramente el Estado como responsable civil subsidiario, ya que no existe una responsabilidad ilimitada del operador ${ }^{66}$.

MARÍN, C., "La producción de electricidad de origen nuclear en España", Boletín de la A.G.E., núm. 33, 2002, pp. 65-77.

64 "El coste de Fukushima: 100000 millones de Euros", El Mundo, (2012, 7 de noviembre). Recuperado el 20 de enero de 2015, de http://www.elmundo.es/elmundo/2012/11/07/internacional/1352269892.html

${ }^{65}$ INSTITUT DE RADIOPROTECTION ET DE SÛRETÉ NUCLÉAIRE, Examen de la méthode d'analyse coût-bénéfice pour la sûreté, 2007. Recuperado el 23/01/2015 de http://www.irsn.fr/FR/Actualites_presse/Actualites/Documents/IRSN_Etude-2007-Cout-Accident.pdf

${ }^{66}$ RUIZ DE APODACA, A., “El marco jurídico...," cit., p. 173. 
Evidentemente, ninguna compañía aseguradora va a establecer una cobertura de una envergadura tal como para hacer frente a un accidente nuclear. En este sentido, en palabras de Ulrich BECK:

Cuando las compañías de seguros niegan su cobertura -como ocurre con la energía nuclear y los nuevos desarrollos de la ingeniería genética- se traspasa la frontera entre los riesgos calculables y los peligros incalculables. Estos potenciales de peligro son generados industrialmente, externalizados económicamente, jurídicamente individualizados, técnicamente legitimados y políticamente minimizados. Dicho de otro modo: entre el sistema normativo de control "racional" y los potenciales de autodestrucción desencadenados existe la misma relación que entre los frenos de una bicicleta y un avión intercontinental ${ }^{67}$.

Respecto al coste de gestión de residuos, es cierto que es una valoración que debe realizar la entidad que los genere ya que, según el Real Decreto 102/2014, de 21 de febrero, para la gestión responsable y segura del combustible nuclear gastado y los residuos radiactivos, es la propia entidad generadora quien debe soportar dicho coste. El problema se plantea aquí en el hecho de que no existe una solución definitiva para los residuos y que los costes que se programan están enfocados a la gestión temporal o a medio plazo. Asimismo, es necesario mencionar que incluso en la Sentencia de la AN, de 30 de junio de 2011, sobre el cese definitivo de la central nuclear de Garoña, se tomaron en consideración ciertas "especificidades" de la generación energética nuclear tales como un "alto grado de incertidumbre" en la "gestión futura de dichos residuos" Como advierte Kristin S. SHRADER-FRECHETTE: "No tener en cuenta los costes de la gestión de residuos nucleares en la valoración económica de la generación de energía eléctrica de origen nuclear implica que, en relación a otro tipo de alternativas energéticas, la Energía nuclear pueda ser más viable económicamente”. A esto mismo se refiere la autora como el "argumento de la ignorancia" 69 .

\footnotetext{
${ }^{67}$ BECK, U., "La industria nuclear contra sí misma”, El País (2011, 5 de abril). Recuperado el 23 de enero de 2015, de http://elpais.com/diario/2011/04/05/opinion/1301954412_850215.html

${ }^{68}$ Sentencia 628/2009, de 30 de junio de 2011, de la Audiencia Nacional.

${ }^{69}$ SHRADER-FRECHETTE, K.S., Energía nuclear..., cit., pp. 66 a 68.
} 


\section{La aplicación del principio de precaución en la industria energética nuclear}

Es necesario advertir de nuevo que, respecto a la industria energética nuclear, los poderes públicos no deciden sobre los riesgos asumibles o no, sino que son las instituciones expertas quienes lo hacen ${ }^{70}$. Esto es así, como hemos comentado en apartados anteriores, debido al alcance del conocimiento que se precisa. Entonces, ¿a qué nivel deben los poderes públicos plantearse aplicar el principio de precaución en la industria energética nuclear? Sin duda, los poderes públicos deberán plantearse la aplicación de dicho principio en cuanto a la posibilidad de contar con dicha energía o no. Es decir, no se trata ya de establecer un marco de protección de mayor alcance, aunque los estudios sobre los efectos estocásticos de un nivel determinado de radiación no sean concluyentes, ni tampoco de legislar sobre el grosor de los edificios de contención de los reactores a fin de evitar daños ante un posible ataque terrorista. Se trata de optar o no por el riesgo cero en cuanto a dicha tecnología. Y esto se debe, básicamente, a que difícilmente se va a conseguir mejorar la opinión del público en general en cuanto a la energía nuclear. No se trata solo de aumentar los niveles de seguridad, sino de que no se confía en la propia industria. La sociedad necesita y tiene derecho a saber a qué nivel de riesgo concreto $^{71}$ se expone y, si este riesgo no puede determinarse, tiene derecho también a elegir si quiere exponerse a él o no. Cuando se anunciaron las propuestas de mejora en la seguridad de todas las centrales nucleares a raíz del accidente de Fukushima, muchos se preguntaron cómo era posible que todavía quedara más margen de seguridad en una industria como la nuclear. Como dije anteriormente, no creo que podamos permitirnos en este sector más ensayos de aciertoerror. El hecho de que la valoración del riesgo de la industria energética nuclear por parte de los expertos haya sido tan distinta de los hechos consumados debería implicar, como mínimo, que los poderes públicos se plantearan la cuestión con la participación pública.

\footnotetext{
70 VILLAMARINO SAMALEA, G., "Derecho de residuos radiactivos y medio ambiente", Documentación administrativa, núm. 256, 2000, p. 210.

${ }^{71}$ Es necesario resaltar las palabras de José Esteve Pardo respecto de la dificultad de valorar jurídicamente el riesgo: “[...] el riesgo tiene una configuración muy diferente a la del daño, sobre todo en lo que a posibilidades de conocimiento se refiere, pues así como el daño se percibe con un conocimiento medio y por ello resulta accesible al jurista -al que sólo pueden escapar ciertos aspectos como pueda ser su cuantificación-, el gran problema del riesgo es su certidumbre: su presencia -y no digamos ya la valoración de su potencialidad y alcance- resulta en muchos casos sólo perceptible a través de un conocimiento técnico especializado del que carece el operador jurídico". ESTEVE PARDO, J., Técnica, riesgo y derecho, Ariel, Barcelona, 1999, p. 81.
} 
A nadie se le escapa que el sector nuclear, tal y como afirma Ángel RUIZ DE APODACA, es un "sector tremendamente regulado e intervenido por una Administración independiente, un organismo regulador, el Consejo de Seguridad Nuclear, y con un régimen de intervención, inspección y sancionador severo" ${ }^{\text {, }}$, pero también es cierto que nunca las consecuencias derivadas de un accidente en una industria tecnológica ha tenido consecuencias tan nefastas para la vida en el planeta. No se trata aquí solo de afectaciones ambientales que pudieran perjudicar a la salud de forma local, sino que, por primera vez, la propia civilización a nivel global se vería amenazada. Hoy día, indudablemente, debemos tratar con otras situaciones que, igualmente, resultan de una problemática ambiental globalizada, como es el caso del efecto invernadero, pero la posibilidad de que, en un período temporal muy breve hablamos de horas, días o semanas-, un accidente en una central produzca una emisión de radiación a la atmósfera que pueda traspasar las fronteras y causar un perjuicio global resulta aterrador para la sociedad.

Por otro lado, es necesario resaltar que las consecuencias de la contaminación tienen aquí un carácter manifiesto de irreversibilidad. No solo podemos valorar la posibilidad o las consecuencias de un accidente nuclear, sino también tenemos que entender que, ante una catástrofe con emisión radiactiva fuera de la instalación - tal y como sucedió en Chernóbyl y Fukushima-, amplias zonas quedarán inhabitables durante miles de años. En este sentido, algunos autores abogan por "proscribir" actividades que puedan suponer "daños graves, irreversibles y catastróficos al medio ambiente",73.

Finalmente, y para recapitular, no solo se hace necesario el establecimiento de las máximas medidas de seguridad a fin de proteger a la población de un accidente nuclear y/o de la radiactividad, sino de poner sobre la mesa la posibilidad de adoptar el

\footnotetext{
${ }^{72}$ RUIZ DE APODACA, A., "Instalaciones nucleares: ponderación de riesgos y necesaria participación en los procesos autorizados", Arana García, E., Mercado Pacheco, P., Pérez Alonso, E. y Serrano Moreno, J. L., Derecho, Globalización y Medio Ambiente, Tirant Lo Blanch, Valencia, 2012, p. 545.

${ }^{73}$ En este sentido, como afirma Zlata Drnas de Clément: "Cuando se teme un daño grave, irreversible o catastrófico, la actividad debe proscribirse; cuando el daño esperado implica una afectación de los bienes ambientales, la actividad debe ser limitada, controlada, condicionada a la relación costo-beneficio, de conformidad a las previsibilidades disponibles, permanentemente actualizadas", en DRNAS DE CLEMENT, Z., "La práctica argentina en materia de sustentabilidad ambiental a través de la aplicación del principio de precaución", El principio de precaución ambiental. La práctica argentina (proyecto de investigación), Lerner, Córdoba, Argentina, 2006. Al respecto, cabe mencionar también a Blanca Mendoza Buergo, que advierte: "[...] la precaución sólo se justifica cuando la sospecha va referida a la producción de daños graves y/o irreversibles para bienes de la máxima importancia y de carácter no renovable como la salud y la vida, así como los recursos naturales", en MENDOZA BUERGO, B., "El derecho penal...", cit., p. 329.
} 
principio de precaución en su máxima expresión, o sea, prohibir una actividad cuyas consecuencias pueden ser, como se ha mencionado, "graves, irreversibles y catastróficas" $"$.

\section{LA DIALÉCTICA ENTRE EL RIESGO Y EL BENEFICIO. LA ENERGÍA NUCLEAR COMO GARANTÍA DE SUMINISTRO ELÉCTRICO}

Hasta aquí hemos analizado las incertidumbres en cuanto al uso de tecnología nuclear para la generación de energía, pero, tal y como afirma José ESTEVE PARDO -y en ello estamos de acuerdo-, el "riesgo cero" ${ }^{, 75}$ no existe y, como caso paradigmático, expone el correspondiente a la energía, en el cual, si renunciamos a uno de los sistemas de producción, nos encontraremos con una situación en la que, necesariamente, haremos de hacer frente a otros riesgos, ya sea de garantía de suministro o de cualquier otro tipo de contaminación $^{76}$.

En España parece claro que la política en cuanto a la cuestión energética nuclear es la de “esperar y ver". Ciertamente, se trata de una cuestión que, gobierno tras gobierno, se ha ido evitando en cierta manera y prueba de ello es que actualmente nuestra Ley de Energía Nuclear (LEN) es una normativa aprobada — si bien modificada posteriormente en numerosas ocasiones - en la remota fecha del 29 de abril de 1964. Parece lógico pensar que los sucesivos gobiernos han evitado "embarcarse" en un proyecto de renovación legislativa que supondría, como es lógico, tomar la decisión de un claro "sí o no" respecto a la utilización de tecnología nuclear para generar energía ${ }^{77}$.

\footnotetext{
${ }^{74}$ Es interesante valorar aquí el caso de Alemania, que ha puesto fecha de caducidad a su parque energético nuclear y va a realizar su planificación futura sin este. AGENCIA EFE, "El Bundestag alemán aprueba por amplia mayoría el "apagón" nuclear para 2022", El Mundo, (2011, 30 de junio). Recuperado el 24 de enero de 2015, de http://www.elmundo.es/elmundo/2011/06/30/natura/1309416722.html

${ }^{75}$ José Esteve Pardo afirma que "el hecho de que el riesgo cero no existe se trata ya de un dato y presupuesto jurídico inequívoco: una firme posición jurisprudencial compartida por tribunales de todas las jurisdicciones, nacionales y europeos". ESTEVE PARDO, J., "Las decisiones normativas sobre riesgos nucleares. Marco constitucional", Doménech Pascual, G. (coord.), El futuro de la energía nuclear en España. Perspectivas (no) sólo jurídicas, Tirant Lo Blanch, Valencia, 2013, pp. 69 a 84.

${ }^{76}$ Efectivamente, el hecho de renunciar a la energía nuclear implicaría, para conseguir una garantía en el suministro, aumentar necesariamente el parque de energías alternativas o, en cualquier caso, las opciones del gas y el carbón. En este último caso, nos encontraríamos de nuevo ante un dilema respecto de las emisiones de efecto invernadero.

${ }^{77}$ Es interesante citar el artículo "La energía nuclear en un Estado social y democrático de derecho", de Gabriel DOMÉNECH PASCUAL, en el cual se analiza la regulación energética nuclear en España y la aplicación del principio de legalidad en dicha actividad, ya que afecta a derechos fundamentales (vida, salud, etc. En este sentido, realiza una comparación con la regulación alemana y la célebre Sentencia
} 
Para ponernos en situación actual, podemos citar el artículo 79.3.c) de la reciente Ley 2/2011, de 4 de marzo, de Economía Sostenible, que establece los objetivos de planificación energética para el año 2020. Según dicho artículo: "Determinar los niveles de participación de la energía nuclear en la cesta de generación energética, de acuerdo con el calendario de operación de las centrales existentes y con las renovaciones que, solicitadas por los titulares de las centrales, en el marco de la legislación vigente, en su caso correspondan, teniendo en cuenta las decisiones del Consejo de Seguridad Nuclear sobre los requisitos de seguridad nuclear y protección radiológica, la evolución de la demanda, el desarrollo de nuevas tecnologías, la seguridad del suministro eléctrico, los costes de generación eléctrica y las emisiones de gases de efecto invernadero, y ateniéndose en todo caso al marco de referencia establecido por la normativa europea vigente, 78 .

Evidentemente, parece que el Estado cuenta con la generación energética nuclear a medio plazo, por lo menos en lo que se refiere a las autorizaciones de renovación ${ }^{79}$, pero desde el punto de vista normativo nos encontramos con un amplio margen de incertidumbre jurídica en cuanto a las autorizaciones de nueva instalación. Así, tal y como advierte Juan Manuel AYLLÓN, "la decisión administrativa —en cuanto a la apertura de una nueva instalación - se debe sustanciar, por tanto, en un análisis costebeneficio que sopese los parabienes que la instalación va a aportar, por un lado, y el mayor impacto radiológico, por otro" ${ }^{\text {} 80}$.O sea, la discrecionalidad administrativa es aquí evidente ya que, en función de las planificaciones energéticas pertinentes — que, por cierto, no tienen carácter normativo sino que son meros instrumentos de planificación que pueden programarse-, será la autoridad pública quien determine la puesta en marcha o no del proyecto. Con respecto a esto, las últimas decisiones políticas en cuanto a la industria energética nuclear hacen suponer que, ciertamente, proyectar la

Kalkar, del Tribunal Constitucional Federal, en la cual se consideró que, efectivamente, "en el campo de los derechos fundamentales, el legislador está obligado a adoptar él mismo todas las decisiones esenciales". DOMÉNECH PASCUAL, G., "La energía nuclear en un Estado social y democrático de derecho", Doménech Pascual, G. (coord.), El futuro de la energía nuclear en España. Perspectivas (no) sólo jurídicas, Tirant Lo Blanch, Valencia, 2013, pp. 85 a 110.

${ }^{78}$ Ley 2/2011, de 4 de marzo, de Economía Sostenible. BOE, núm. 55, de 5 de marzo de 2011.

${ }^{79}$ Aunque es necesario precisar aquí la poca seguridad jurídica que se deduce también a raíz de las renovaciones. A tal efecto, cabe mencionar la Orden ITC/1785/2009, de 3 de julio, por la que se acuerda como fecha de cese definitivo de la explotación de la Central Nuclear de Santa María de Garoña el día 6 de julio de 2013, y se autoriza su explotación hasta dicha fecha, en la cual no se otorgó la renovación para los 10 años que solicitaba la empresa gestora.

${ }^{80}$ AYLLÓN DÍAZ-GONZÁLEZ, J. M., Derecho..., cit., p. 385. 
construcción de una central nuclear en España sea un indudable acto de "valentía" empresarial.

Podemos citar al caso la central nuclear de Garoña ${ }^{81}$, inaugurada en 1970, cuya nueva reapertura tras su cierre "definitivo" en 2012 debido, en palabras de la empresa gestora, a "incertidumbre" regulatoria ${ }^{82}$, ha sido propuesta por el actual Gobierno hasta el año 2031, encontrándose hoy día a la espera del preceptivo informe del Consejo de Seguridad Nuclear ${ }^{83}$. Si, finalmente, la reapertura se hace efectiva, ello implicaría que la vida útil de las centrales quedaría establecida en 60 años. Y si así sucediera, es lógico pensar que el Gobierno cuenta con la energía nuclear en su planificación energética mucho más allá del medio plazo que marca la Ley de Economía Sostenible.

Dejando a un margen las actuaciones de los sucesivos gobiernos en cuanto a la cuestión energética nuclear, lo que tratamos es de ponderar de forma efectiva los beneficios ${ }^{84}$ que supone la energía nuclear en contraposición a la incertidumbre sobre sus riesgos $\operatorname{asociados}^{85}$. En este sentido, parece claro que la energía nuclear provee de un suministro energético estable ${ }^{86}$, capaz de responder a picos de demanda de forma fiable. Es esta una de las ventajas que dificulta en gran medida la sustitución a corto plazo por otro tipo de energías alternativas, ya que para cualquier Estado la garantía y seguridad del suministro suponen una cuestión estratégica de primer nivel. Por otro lado, los precios del uranio son más estables que los de los combustibles fósiles, y se estiman unas

\footnotetext{
${ }^{81}$ Mediante la Sentencia de 30 de junio de 2011, la Audiencia Nacional desestimó los recursos contencioso-administrativos que la empresa gestora de la central interpuso contra la Orden del Ministerio de Industria, Comercio y Turismo, por la cual se renovaba la autorización de explotación de la central por un período de tres años. La AN justificaba la decisión sobre la base, entre otras consideraciones, de que el capital invertido estaba amortizado y la política del Gobierno era aumentar el peso de las energías renovables.

${ }^{82}$ AGENCIA EFE, "La empresa que gestiona Garoña pide no renovar ante la "incertidumbre regulatoria", El Mundo (2012, 5 de septiembre). Recuperado el 24 de enero de 2015, de http://www.elmundo.es/elmundo/2012/09/05/economia/1346881197.html

${ }^{83}$ ABASCAL, P., "El Gobierno reabrirá la central nuclear de Garoña tras el cierre de Zapatero", $A B C$ (2014, 28 de mayo). Recuperado el 24 de enero de 2015, de http://www.abc.es/sociedad/20140528/abcigarona-reapertura-central-nuclear-201405272342.html

${ }^{84}$ Podemos encontrar un análisis de las ventajas e inconvenientes de la energía nuclear en GONZÁLEZ ROMERO, E. M., y RUIZ HERNÁNDEZ, V., Energía nuclear, CSIC, Madrid, 2010.

${ }^{85}$ Para Carl Sunstein: "El análisis de costo-beneficio se ha vuelto una herramienta cada vez más popular para la evaluación y el manejo de los riesgos sociales. De hecho, este tipo de análisis con frecuencia se utiliza como alternativa al principio de precaución. Se sostiene que, en vez de tomar precauciones ciegamente, las autoridades reguladoras deberían calcular los beneficios de la regulación y sus costos y elegir el enfoque que maximice los beneficios netos". SUNSTEIN, C. R., Leyes del miedo..., cit., p. 179.

${ }^{86}$ En el caso de las energías alternativas, como la eólica, es lógico suponer que en condiciones de estabilidad atmosférica no habría generación eléctrica estable.
} 
abundantes reservas ${ }^{87}$. Asimismo, cabe mencionar que en los últimos años se ha tomado en consideración que la energía nuclear es una energía limpia por cuanto no genera emisiones de gases de efecto invernadero ${ }^{88}$, a diferencia de la energía proveniente de combustibles fósiles.

Sobre esto último, es cierto que la generación de energía eléctrica a partir de la fisión nuclear es una operación que, en sí misma, no emite gases de efecto invernadero, pero habría que realizar un estudio mucho más detallado -y no partidista- sobre todas las fases de la producción eléctrica nuclear, desde la extracción del mineral hasta el proceso de fisión, para valorar efectivamente las emisiones de gases de efecto invernadero de la industria nuclear y poder relacionarlas con el resto de las tecnologías energéticas.

El Estado tiene dos opciones en estos casos: aplicar de forma tajante el principio de precaución en el sentido de considerar las consecuencias más graves e irreversibles de la utilización energética nuclear — la posibilidad de un accidente con emisión radiactiva al exterior-, así como la incertidumbre en cuanto al tratamiento de los residuos nucleares en el futuro; o aplicar el principio de justificación ${ }^{89}$, lo que supondría que el Estado ha considerado que el beneficio social justifica en cierta manera adoptar los riesgos que se presuponen, por lo que, cumpliendo las normas legales de seguridad nuclear, protección radiológica, gestión de residuos y no proliferación, concibe en la planificación energética futura la inclusión de la energía nuclear. Este último caso, valorando las actuales políticas administrativas y legislativas, sería el de España.

Por supuesto, hay que entender que la aplicación del principio de precaución en relación con la industria energética nuclear es una cuestión puramente política, y, en consecuencia, el hecho de contar o no con dicha tecnología para la generación de

\footnotetext{
${ }^{87}$ Algunos autores difieren en este punto y afirman que las reservas de uranio económicamente viables de extraer son mucho menores. Vid. GONZÁLEZ ROMERO, E. M., y RUIZ HERNÁNDEZ, V., Energía..., cit., pp. 17 y 18 .

${ }^{88}$ En este sentido, algunos ecologistas como Patrick Moore o James Lovelock han afirmado que la energía nuclear es, actualmente, la única opción si queremos salvar el planeta de los efectos del calentamiento global. MOORE, P., "A green makes the case", Whashington Post (2006, 16 de abril). Recuperado el 24 de enero de 2015, de http://www.washingtonpost.com/wpdyn/content/article/2006/04/14/AR2006041401209_pf.html

${ }^{89}$ Juan Manuel Ayllón habla del principio de justificación y comenta que no se trata solo de que la industria nuclear emita por debajo de los límites legales, sino que esas emisiones deben estar justificadas con un beneficio social. En este caso, es cada Estado quien debe ponderar los argumentos. AYLLÓN DÍAZ-GONZÁLEZ, J. M., Derecho..., cit., pp. 574 a 576.
} 
energía será una valoración de cada gobierno en particular $^{90}$. El derecho no establece el nivel de riesgo al que debe someterse una sociedad, sino que son los poderes públicos quienes deben valorar y decidir cuál es el nivel de riesgo aceptado y, en relación con ello, legislar adecuadamente ${ }^{91}$.

Ahora bien, ¿cómo se ha realizado tal ponderación entre riesgo y beneficio? Es lógico pensar que los fundamentos que admiten los riesgos asociados a la generación energética nuclear — como la garantía de suministro o la libertad empresarial— son de menor envergadura que los fundamentos que cimentarían la adopción de una postura en contra de dichos riesgos — derecho a la salud y a un medio ambiente adecuado ${ }^{92}$. Además, en tiempos recientes se ha incluido también la posibilidad de que la energía nuclear sea la "panacea" para la lucha contra el calentamiento global, y esto se ha convertido en la bandera de los pronucleares de hoy día. De cualquier modo, lo que se percibe - al menos a nivel político - es que la incertidumbre respecto de la garantía de suministro contrarresta en gran medida la situación de incertidumbre en cuanto a los riesgos asociados y coloca a los poderes públicos en la tesitura de, manteniendo los niveles teóricos actuales de dichos riesgos ${ }^{93}$, garantizar la capacidad de suministro energético para los próximos años ${ }^{94}$.

Evidentemente, en los primeros estadios de la energía nuclear en nuestro país, no se abordaron y se analizaron detalladamente, ponderándolos con los beneficios asociados, los riesgos que conllevaría la utilización de tecnología nuclear para la generación de energía. Todo esto por las razones esgrimidas en el primer apartado de este trabajo: confianza "ciega" en dicha tecnología, visión estratégica en el sector energético, etc. En

\footnotetext{
${ }^{90}$ Tal y como comenta Ángel Ruiz de Apodaca, “el Derecho actual no impone ninguna de las opciones energéticas en liza, la decisión sobre la energía nuclear es puramente política, los poderes públicos gozan de entera libertad para configurar la política nuclear que estimen convenientemente en cada momento". RUIZ DE APODACA, A., “E1 marco jurídico...”, cit., p. 120.

${ }^{91}$ En relación con esto, José Esteve Pardo señala: “[...] el riesgo es, ha de ser, objeto de atención y regulación, materia del Derecho en la medida en que se integra de acciones y decisiones humanas de las que somos responsables". ESTEVE PARDO, J., "Las decisiones...”, cit., p. 70.

${ }^{92}$ Para otro análisis sobre los inconvenientes de la generación energética nuclear, vid. CALDICOTT, H., Nuclear power is not the answer, New Prest, Nueva York, 2006.

${ }^{93}$ Como hemos comentado anteriormente, todo ello sin proyectar ninguna nueva instalación — salvo el necesario ATC - y manteniendo renovado el parque energético nuclear actual.

${ }^{94}$ Tanto es así que, recientemente, el Gobierno de Japón decidió volver a retomar la energía nuclear como fuente energética nacional, ya que le resulta "barata" en costes operativos y, además, garantiza el suministro estable. "El gobierno de Japón decide volver a apostar por la energía nuclear", La Vanguardia (2012, 11 de abril). Recuperado el 25 de enero de 2015, de http://www.lavanguardia.com/natural/20140411/54404917756/el-gobierno-de-japon-decide-volver-aapostar-por-la-energia-nuclear.html
} 
cualquier caso, hay que decir que la regulación en materia de energía nuclear está basada en una normativa, como no puede ser de otra forma, altamente intervenida y sometida a un amplio "elenco de autorizaciones" 95 , y que el aspecto de la seguridad es la principal razón de ser de dicha reglamentación ${ }^{96}$. Pero, y seamos claros en esto, es cierto que no podemos permitirnos un riesgo cero ${ }^{97}$ en ninguna tecnología, ya que nos haría volver a situaciones de vulnerabilidad casi "prehistóricas". Sin embargo, la cuestión es si debemos aceptar incluso ese nivel ínfimo -tal y como nos indican los expertos- de riesgo ante algo tan incontrolable, destructor e irreversible como los accidentes nucleares de Chernóbyl y Fukushima.

La cuestión es sumamente difícil de valorar, pero se hace necesario pensar que tal vez sea el momento de reflexionar no solo en el desarrollo de sistemas energéticos que puedan hacer frente a nuestra demanda con los menores riesgos asociados - tales como las energías alternativas - , sino también en el desarrollo de programas de eficiencia energética que puedan disminuir los riesgos de garantía de suministro tan temidos por los Estados desarrollados ${ }^{98}$.

\section{LA LEGITIMIDAD DE LA DECISIÓN FINAL. EL PESO DE LA OPINIÓN PÚBLICA}

Ahora bien, podemos hacer referencia a otra cuestión polémica que provoca una discusión de creciente importancia: la legitimidad de la valoración previa a la decisión final y la de la propia decisión final. En este sentido, podemos plantearnos también las siguientes cuestiones: ¿qué institución valora o estima el riesgo ${ }^{99} \mathrm{y}$, no menos importante, ¿es esta valoración extrapolable al sentir común de la sociedad?

\footnotetext{
${ }^{95}$ RUIZ DE APODACA, A., "El marco jurídico ...", cit., p.143.

${ }^{96}$ AYLLÓN DÍAZ-GONZÁLEZ, J. M., en Derecho..., cit., p. 39.

${ }^{97}$ Lidia María Rosa Garrido Cordobera aborda el problema de la imposibilidad del riesgo cero, pero también advierte de la necesidad de valorar en estos casos la evitación del daño. GARRIDO CORDOBERA, L. M. R., El riesgo ambiental, Reus, Madrid, 2014, p. 49.

${ }^{98}$ Respecto a esto, es necesario preguntarse hasta qué punto se hubieran desarrollado las energías alternativas con las inversiones realizadas en energía nuclear. En palabras de Marcel Cordech: "La reactivación nuclear, en contra, agravaría el problema energético por lo siguiente: cuantiosas inversiones que impedirían recurrir a otras alternativas, y alejamiento de la posibilidad de un cambio cultural", en ALMIRÓN, N. y CORDECH, M., El espejismo nuclear, Los Libros del Lince, Barcelona, 2008.

${ }^{99}$ Leandro del Moral y María Fernanda Pita abordan el problema de la decisión sobre los riesgos. En este sentido, afirman que "en el centro del debate sobre el riesgo se sitúan las cuestiones relacionadas con la capacidad de decisión, con el poder: una de las mayores preocupaciones del debate actual sobre los
} 
La importancia de la primera cuestión radica en que, para decidir adecuadamente sobre una determinada tecnología, es lógico tener conocimiento del riesgo asociado que conlleva. Este conocimiento permitiría a la Administración pública legislar de forma adecuada acerca de una determinada aplicación tecnológica que pudiera afectar a las personas o al medio ambiente, pero, debido sobre todo a la complejidad tecnológica y a la falta de soluciones viables a largo plazo - me refiero aquí a la gestión de los residuos radiactivos - , no resulta un conocimiento tan preciso en el caso del sector nuclear. Evidentemente, se trata de un sector cuya complejidad tecnológica sobrepasa la capacidad de la Administración. Por ello, existe un "poder científico o experto" que desempeña las funciones de evaluación y gestión de riesgos en el sector nuclear ${ }^{100}$. En España, el organismo encargado del asesoramiento y control de la seguridad de las instalaciones nucleares es el CSN. A nivel internacional, aparece el Organismo Internacional de la Energía Atómica (OIEA), cuyas normas y recomendaciones, aunque no directamente aplicables en el Estado, deben tomarse en consideración ${ }^{101}$.

El CSN tiene potestad para "elaborar y aprobar las instrucciones, circulares y guías, de carácter técnico relativa las instalaciones nucleares y radiactivas y las actividades

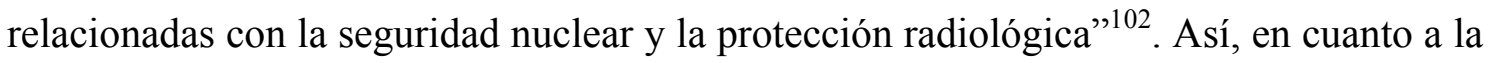
seguridad de las instalaciones, el principal instrumento son las guías de seguridad, las cuales, aunque bajo el aspecto de meras recomendaciones ${ }^{103}$, poseen un claro efecto vinculante dado que la propia normativa y las autorizaciones suelen remitirse a dichas guías. En consecuencia, la legislación nuclear está escasamente dotada de criterios específicos en cuanto a la seguridad, siendo el CSN el organismo que establece y

riesgos es, precisamente, cómo y con qué criterios se deben adoptar las decisiones sobre el riesgo, quién tiene que asumir las responsabilidades que tales decisiones comportan, quién garantizará cierta seguridad si las cosas no funcionan bien, cómo y con qué recursos se conseguirá que así sea. En este sentido los riesgos se convierten cada vez más en el espejo en el cual se reflejan con fidelidad las relaciones que se establecen entre el hombre y su medio, y entre los hombres entre sí”, en DEL MORAL, F., y PITA, M., "El papel de los riesgos en las sociedades contemporáneas", Cantos, O. y Carcedo, A., Riesgos naturales, Ayala, Barcelona, 2002, pp. 75-88.

${ }^{100}$ RUIZ DE APODACA, A., "El marco jurídico ...”, cit., p.142

${ }^{101}$ España ratificó la Convención sobre la Seguridad Nuclear el 19 de junio de 1995. Esta convención tiene un evidente carácter "contractual" sobre los Estados firmantes.

102 Artículo 2.a de la Ley 15/1980, de 22 de abril, de creación del Consejo de Seguridad Nuclear (LCSN).

${ }^{103}$ Así lo recoge Juan Manuel Ayllón cuando indica que "su incumplimiento determina la actitud de reproche del CSN en el ejercicio de sus competencias”. AYLLÓN DÍAZ-GONZÁLEZ, J. M., Derecho..., cit., p. 526. 
controla los niveles de seguridad de las instalaciones y, paralelamente, el nivel de riesgo que puede asumirse.

Podemos encontrarnos, además, con otro ámbito de regulación en cuanto al riesgo estimado, que sería el que corresponde al propio sector ${ }^{104}$. Evidentemente, en un sector de una complejidad tecnológica como el de la energía nuclear, será la propia industria quien esté en condiciones de emitir juicios prácticos —en este sentido, recomendaciones y códigos - en cuanto a la seguridad en la construcción, puesta en marcha y funcionamiento de una instalación nuclear. Por supuesto, no son normas vinculantes a menos que sean referenciadas en la normativa o en actos autorizadores, pero nadie duda de que la Administración, comprendiendo su limitación sobre el conocimiento técnico de la industria nuclear, asume los dictámenes de la propia industria y de los organismos expertos. Así, el "riesgo asumible"105 no es fruto de una valoración por los poderes públicos, sino de una valoración de los organismos expertos ${ }^{106} \mathrm{y}$ del sector industrial privado.

La inclusión de la segunda cuestión acerca de la estimación social del riesgo merece una explicación, ya que la sociedad puede percibir que el riesgo es distinto de lo que la institución experta hace constar en sus informes. Efectivamente, respecto a la energía nuclear, el sentir general de la sociedad es que supone un riesgo mayor que el valorado

\footnotetext{
104 Así, Ángel Ruiz de Apodaca afirma que "no se puede negar la eficacia vinculante de la autorregulación no desde un punto de vista jurídico pero sí desde un punto de vista práctico, real". RUIZ DE APODACA, A., "El marco jurídico..., cit., p.185.

${ }^{105}$ Con esta expresión, Vicente Serradell García conceptúa el límite de la seguridad nuclear, en relación con factores tecnológicos, económicos y sociológicos, SERRADELL GARCÍA, V., "Seguridad Nuclear: conceptos y métodos", ponencia presentada en el curso de la UIMP Seguridad Nuclear y reactores avanzados, Tomo II, Valencia, julio de 1991, p. 3.

${ }^{106}$ Es importante destacar que en la actualidad la Administración se encuentra en ciertos ámbitos "superada" por el conocimiento que se precisa para su adecuada regulación jurídica. En este sentido, lo que a principios del s. XX consistía en labores de policía encaminadas a minimizar los efectos de la industria sobre las personas, en décadas posteriores fue derivando hacia otro tipo de gestión en relación con el progreso técnico. José Esteve Pardo reflexiona sobre las referencias características de la respuesta del derecho ante los riesgos, y compara la tradicional actuación ante "perturbaciones o molestias" con la respuesta ante los actuales factores de riesgo que, en comparación, no solo afectarían singularmente a la sociedad, sino también a nivel global. En este sentido, toma tres referencias al respecto: el elemento subjetivo -la Administración ordinaria- que, en cierta manera, carece de conocimiento científico y técnico para abordar la nueva situación, por lo que se tienden a crear administraciones especializadas e independientes - CSN- o, incluso, se trasladan las funciones -sobre todo de control e inspección- a sujetos particulares -TÜV en Alemania-; una referencia conceptual, antiguamente enmarcada en el concepto de policía, y que actualmente se configura como un modelo de gestión de riesgos, "más allá de la pretensión, ya utópica, de su total eliminación"; y, por último, una referencia instrumental, que aborda, entre otras, la cuestión de la responsabilidad, la referencia al "estado de la técnica" como cláusula normativa, y la búsqueda de fórmulas de cooperación para el tratamiento jurídico de los riesgos. ESTEVE PARDO, J., Técnica, ..., cit., pp. 59 a 75.
} 
por los expertos ${ }^{107}$. Ahora bien, podemos suponer que esta valoración social del riesgo está influenciada por medios de comunicación "hambrientos" de radioyentes, televidentes o lectores, pero ¿no es cierto que el número de accidentes graves ya ha superado el nivel de riesgo estimado ${ }^{108}$ ? La permanencia de las consecuencias de un accidente nuclear grave estará presente en cada aniversario de este, y no solo en los medios de comunicación que lo recuerdan, sino también en el medio ambiente y en las poblaciones cercanas a las "zonas cero". Esto es lo que deben considerar los expertos y los poderes públicos, ya que ellos son la "llave" para establecer el debate necesario y para informar de manera objetiva a la opinión pública. Eso sí, nadie puede creer que la probabilidad estimada por los expertos es que un accidente nuclear grave ocurrirá cada millón de años/reactor ${ }^{109}$. El experto, en este sentido, no debería alejarse del interés común y escudarse en probabilidades teóricas partidistas, cuando es evidente que existe una incertidumbre inherente a la complejidad del propio sistema tecnológico.

Por supuesto, también la opinión pública deberá valorar las consecuencias en cuanto al problema de la garantía de suministro, y deberá ser informada sobre las opciones energéticas y sus respectivas problemáticas. Las instituciones deben plantearse que no es necesario el conocimiento técnico del público para intervenir en el debate, sino su capacidad para juzgar lo que los expertos y la Administración pongan sobre la mesa ${ }^{110}$. Al fin y al cabo, es la sociedad quien asumirá las consecuencias de la decisión final ${ }^{111}$.

\footnotetext{
${ }^{107}$ Sobre el asunto de la percepción social del riesgo en cuanto a la energía nuclear, vid. ALONSO, A., "Sobre la energía nuclear y la percepción de sus riesgos", Ambienta: La revista del Ministerio de Medio Ambiente, núm. 36, 2004, pp. 37-43.

${ }^{108}$ En este sentido, el Instituto Max Planck de Química de Mainz, Alemania, publicó un informe el 22 de mayo de 2012 en el cual se afirmaba que la probabilidad de accidentes catastróficos en centrales nucleares es mayor de lo que se preveía hasta ahora, MAX-PLANCK-GESELLSCHAFT, Probability of contamination from severe nuclear reactor accidents is higher tan expected. Recuperado el 26 de enero de 2015, de http://www.mpg.de/5809418/reactor_accidents

${ }^{109}$ Esta probabilidad fue estimada por el Informe Rasmussen en 1975 para el estudio de la seguridad de los reactores nucleares, CASAL, J., MONTIEL, H., PLANAS, E., y VÍLCHEZ J. A., Análisis del riesgo en instalaciones industriales, Universitat Politècnica de Catalunya, Barcelona, 1999.

${ }^{110}$ Podemos encontrar un análisis sobre la capacidad social para el debate público en DEWEY, J., La opinión pública y sus problemas, Morata, Madrid, 2004 [1927].

${ }^{111}$ Para Javier Serrano Martínez, "la producción y la complejidad de la ciencia y la tecnología son de tal calibre que la intervención única de los expertos no puede asegurar siquiera su mero conocimiento, mucho menos el análisis de los riesgos asociados o los efectos combinados sobre aspectos de la convivencia social. Pero, aunque pudieran llegar a disfrutar de un tiempo infinito para una tarea tan inmensa, necesitarían de las directrices de las que pudieran servirse para poder decidir la ciencia y la tecnología más convenientes para la mejora de la vida cotidiana, al margen de sus perspectivas personales, morales o éticas. El bienestar social que hay que perseguir ha de ser consensuado, y dicho bienestar es objeto de grave afectación por el desarrollo científico y tecnológico. El consenso requiere debate y crítica a las diversas opciones, y este proceso requiere información y formación por parte de los
} 
Tenemos que pensar que en España no ha habido un verdadero debate en cuanto a la opción energética nuclear. En nuestro país, la industria energética nuclear actual es "heredera" de la política franquista, que, por supuesto, no dio pie a un debate público respecto a ella. Y hoy día, como hemos comentado, la situación está marcada por cierto temor del Gobierno a tomar una decisión al respecto. Por supuesto, determinados sectores pueden criticar el debate público basándose en que, si fuera necesario recabar la opinión pública para aprobar cualquier utilización tecnológica, se incurriría en una parálisis tecnológica que afectaría al progreso y al bienestar social. A ello se puede responder con lo que he venido repitiendo en los apartados anteriores: las consecuencias de los accidentes nucleares y de la gestión de los residuos podrían suponer un coste humano, ambiental y económico extraordinario, que afectaría a las generaciones presentes y futuras. A todo esto hay que sumar que existen alternativas que, en principio, pueden resultar efectivas para garantizar el suministro y cuya existencia justificaría por sí sola el debate sobre la opción energética ${ }^{112}$.

En otro orden de cosas, y dejando a un lado los aspectos éticos que legitimarían un debate en torno a la opción nuclear, es necesario adoptar también una postura jurídica en cuanto al concepto de responsabilidad para legitimar dicho debate. En este sentido, uno de los principios fundamentales del derecho ambiental es el llamado principio de colaboración — junto con los principios de prevención y de precaución-, mediante el cual se satisface la asunción de los riesgos por la comunidad, a fin de hacer efectiva la responsabilidad por el cumplimiento del derecho ${ }^{113}$. Por ello, respecto al sector nuclear, planteo aquí la necesidad de una decisión pública firme sobre su utilización como suministro eléctrico en consideración a la responsabilidad subsidiaria del Estado, tal y como se ha especificado en el apartado III.4 de este trabajo. Es decir, no sería ni ética ni

individuos [...]. Sólo el político informado podrá tomar decisiones en nombre de sus ciudadanos, solo en estos términos parecería adecuado ejercer la representación que la democracia le otorga legítimamente como representante electo". SERRANO, J., Ciencia..., cit., p. 51.

${ }^{112}$ Me refiero aquí a las energías alternativas. El apoyo definitivo del Gobierno español a estas, tal y como ha hecho Alemania, podría resultar clave para dar el impulso necesario a este tipo de energías en nuestro país.

${ }^{113}$ Así, Jordi Jaria i Manzano afirma "El Estado de Derecho se manifiesta, en este contexto, a través del principio de responsabilidad, según el cual los riesgos que se materializan a través del cumplimiento del Derecho son asumidos por la comunidad, mientras que los que se concretan como consecuencia de la violación del Derecho son asumidos por el infractor, haciéndose efectiva la seguridad jurídica, que, probablemente, sea el elemento fundamental del Estado de Derecho", en JARIA I MANZANO, J., "El fundamento constitucional de los derechos de participación en materia de medio ambiente y su desarrollo en la Ley 27/2006", Pigrau Solé, A., Acceso a la información, participación púbica y acceso a la justicia en materia de medio ambiente: diez años del Convenio de Aarhus, Atelier, Barcelona, 2009, p. 121. 
jurídicamente aceptable que la comunidad asuma el coste aparejado ${ }^{114}$ a un accidente nuclear grave si previamente no se ha debatido ni determinado firmemente en el Parlamento -o, como han hecho otros Estados, a través de referéndum- la aceptación de la opción energética nuclear.

En relación con lo anterior, para David SCHWEICKART, la decisión democrática en la elección energética es indudable, ya que, según afirma, el enorme capital necesario para la gestión de esta conlleva que, necesariamente, tenga que ser debatida en el Parlamento ${ }^{115}$ —en consideración a lo que llama "Democracia Económica". Este punto de vista economicista es necesario, pero, por supuesto, hay que tener en cuenta otros elementos en cuanto a las decisiones sobre la energía nuclear, ya que, tal y como afirman José ESTEVE PARDO y Gabriel DOMÉNECH PASCUAL ${ }^{116}$, la posibilidad de afectación a derechos fundamentales, a bienes públicos —medio ambiente- y a las generaciones futuras hace necesario que el Estado adopte una clara orientación en cuanto a la opción energética nuclear, valorando no solo la controversia del "a favor" o “en contra", sino también las condiciones de renovación de las centrales actualmente en funcionamiento a fin de mantener una planificación energética efectiva.

De esta forma se justifica la posición de debate público y clara orientación del Estado sobre el sector energético nuclear sobre la base no solo de la protección jurídica de los mencionados derechos fundamentales — si bien es indudable que sería el aspecto más

\footnotetext{
${ }^{114}$ Para Carl Sunstein, el análisis coste-beneficio sobre la aceptabilidad de la utilización de tecnología asociada a riesgos podría ser útil para valorar las opciones, aunque advierte: "No sostengo que el análisis de costo-beneficio debería controlar las decisiones regulatorias, pues dicho análisis no establece una regla por la cual se deba hacer las elecciones. Los participantes de una sociedad democrática podrían optar por proceder incluso cuando los costos exceden los beneficios, pero si lo hacen, debería ser después de recibir la información que brinda el análisis de costo-beneficio. Y si los entes reguladores optan por imponer costos que son desproporcionadamente altos en comparación con los beneficios esperados, deberían explicar por qué eligieron hacerlo", en SUNSTEIN, C. R., Leyes del miedo..., cit., p. 180.

${ }^{115}$ Efectivamente, según afirma el autor, es necesario que la elección sobre la admisión de la energía nuclear se construya en las asambleas nacionales y que, en el laissez-faire, sean las empresas quienes decidan. Para el caso que nos ocupa, la decisión de apostar por la energía nuclear debería ser democrática y, en el caso de ser aprobada en el Parlamento, dejar que sea el sector privado quien decida o no su instalación, acatando la normativa al respecto. SCHWEICKART, D., Más allá del capitalismo, Sal Terrae, Cantabria, 1993 (trad. de Carlos Escriche Blancaflor, 1997), p. 303.

${ }^{116}$ ESTEVE PARDO, J., "Las decisiones...", cit., y DOMÉNECH PASCUAL, G., El futuro de la energía..., cit. En este sentido, Gabriel Doménech Pascual hace una interesante comparación con el caso alemán, analizando la famosa Sentencia de la central de Kalkar. En dicha Sentencia, el Tribunal Federal Alemán consideró que la admisibilidad de la opción energética nuclear debía decidirse en el sentido de reserva de ley por su incidencia sobre las condiciones de vida de los ciudadanos. Vid. al respecto SCHWABE, JÜRGEN, Jurisprudencia del Tribunal Constitucional Alemán. Extractos de las sentencias más relevantes, Konrad-Adenauer-Stiftung e. V., Berlín, 2009, p. 487 (Sentencia BVerfGE 49, 89 [Kalkar I]).
} 
importante-, sino también de la eliminación de la incertidumbre empresarial en el marco del derecho a la libertad de empresa que establece el artículo 38 de la Constitución Española. Así, se tratará también de que la planificación energética que el Estado determine, y que el sector privado materializara, se aplique de forma efectiva con la seguridad del mantenimiento de las opciones planificadas. Es indudable que, por meras razones estratégicas, un Estado debe tener claro cuáles serán sus opciones energéticas futuras desde el actual estado de conocimientos a fin de valorar la tecnología en la que depositará la seguridad del suministro y la efectiva inversión económica. Así, se garantiza también que las empresas puedan invertir en esas opciones económicas con la mínima incertidumbre posible.

\section{CONCLUSIONES}

Es indudable que la industria energética nuclear todavía no ha resuelto los problemas que surgieron desde sus inicios a mediados del s. XX. En la actualidad sigue siendo una fuente de incertidumbre en cuanto a las probabilidades y consecuencias de un accidente nuclear -Fukushima volvió a poner este hecho sobre la mesa, en cuanto a la gestión de los residuos y en cuanto a sus costes económicos. Pero también se ha postulado como una fuente de garantía de suministro eléctrico y como una respuesta "limpia" a la generación energética procedente de los hidrocarburos. A raíz de todo ello surge una tensión entre riesgo y beneficio que, en el caso del Estado español $-\mathrm{y}$ aunque sea ciertamente improbable que el sector privado se "embarque" en proyectos de nuevas instalaciones nucleares de generación de electricidad ${ }^{117}$, permite que se siga confiando en el parque nuclear existente a corto-medio plazo mediante la renovación de las autorizaciones.

Pero el problema de la incertidumbre se ha hecho casi "crónico" en este sector. No se confía en los análisis de riesgos de las instituciones expertas $\mathrm{y}$, menos aún, en que la solución definitiva a los residuos surja a corto plazo. Todas estas inquietudes plantean la posibilidad de una aplicación del principio de precaución en toda su magnitud, es decir, no contar con la tecnología nuclear para la generación de energía y, por tanto, asumir el controvertido "riesgo cero" en cuanto a la utilización de energía nuclear. Esto último, por supuesto, abriría las puertas a otro tipo de riesgos asociados a la pérdida de un

\footnotetext{
${ }^{117}$ La normativa nacional, en principio, no prohíbe la instalación de nuevas centrales nucleares.
} 
sistema generador de alta garantía aunque, en cualquier caso, afectarían a bienes y derechos de menor envergadura, tales como los derechos a la libertad de empresa y al desarrollo económico. Además, si se confía en que en un futuro se desarrollarán sistemas de seguridad mucho más sofisticados para las centrales nucleares, que desaparecerán los residuos nucleares y que los existentes serán tratados adecuadamente, ¿por qué no confiar en que en un futuro las energías alternativas y renovables puedan suplir adecuadamente la pérdida de las nucleares?

De cualquier modo, es necesario resaltar la importancia de una posición jurídicamente estable del Estado respecto de la utilización de la energía nuclear. La controversia social que produce y las incertidumbres inherentes lo requieren. Tal vez la decisión más conveniente sería la de realizar una consulta pública o referéndum a fin de conocer la valoración social general y de tomar en consideración el principio de colaboración, teniendo en cuenta que la responsabilidad de un accidente nuclear con graves consecuencias, así como la gestión futura de los residuos, sin duda será asumida también por la sociedad.

En cuanto a la posibilidad de una consulta, es muy posible que desde ciertos sectores industriales, políticos, sociales, etc., se afirme que gran parte de la sociedad tiene una valoración del riesgo "nuclear" que presenta un cierto grado de subjetividad, y que hace estimar dicho riesgo de forma muy superior a lo que realmente sería lógico. En cuanto a ello, lo primero que hay que responder es que la valoración "objetiva o lógica" se ha demostrado imprecisa en muchas ocasiones, como ya se ha puesto de manifiesto en el apartado III de este trabajo. Si no es posible aceptar la valoración del público, tampoco se han dado motivos para aceptar la estimación experta del riesgo. Lo segundo es que la percepción del riesgo por parte de un individuo forma parte de su entorno vital, y afecta a su potencial bienestar como individuo en una sociedad. Es decir, una persona que estima que el riesgo potencial de que se produzca un accidente nuclear es altamente probable verá disminuida su satisfacción con la vida que lleva. En este sentido, muchas de las personas que viven en áreas cercanas a instalaciones nucleares se ven afectadas por ese miedo y ven disminuida su calidad de vida. No valorar estas situaciones de las minorías más afectadas supone entrar en una tendencia utilitarista que, por supuesto, no toma en cuenta los valores de igualdad. 


\section{BIBLIOGRAFÍA}

ALLENDE LANDA, J., "Política de ubicación de Centrales Nucleares en España", Estudios Territoriales, núm. 17, enero de 1985.

ALMIRÓN, N. y CORDECH, M., El espejismo nuclear, Los Libros del Lince, Barcelona, 2008.

ALONSO, A., "Sobre la energía nuclear y la percepción de sus riesgos", Ambienta: La revista del Ministerio de Medio Ambiente, núm. 36, 2004, pp. 37-43.

ANSPAUGH, L., CATLIN, R., y GOLDMAN, M., "The Global Impact of the Chernobyl reactor accident", Science, vol. 242, diciembre 1988.

ARRANZ, L. y DE ALBORNOZ, C., "Utilización de la energía nuclear: la percepción del riesgo radiológico del público", Revista de Salud Ambiental, núm. 10 (1-2), 2010, pp. 53-56.

AYLLÓN DÍAZ-GONZÁLEZ, J. M., Derecho Nuclear, Comares, Granada, 1999.

BARCELÓ, A., Instalaciones nucleares. Autorización y conflicto, Ariel, Barcelona, 2002.

BECK, U., La sociedad del riesgo. Hacia una nueva modernidad, Paidós, Barcelona, 1998.

BENACH, J., CIRERA, A., y RODRÍGUEZ FARRÉ, EDUARD, ¿Átomos de fiar? Impacto de la energía nuclear sobre la salud y el medio ambiente, Catarata, Madrid, 2007.

BORRÀS PENTINAT, S., "Refugiados ambientales. El nuevo desafío del derecho internacional del medio ambiente", Revista de Derecho, vol. 19, núm. 2, 2006.

CALDICOTT, H., Nuclear power is not the answer, New Prest, Nueva York, 2006.

CANOSA USERA, R., “Aspectos constitucionales del Derecho ambiental”, Revista de Estudios Políticos, núm. 94, 1996.

CASAL, J., MONTIEL, H., PLANAS, E., y VÍlCHEZ J. A., Análisis del riesgo en instalaciones industriales, Universitat Politècnica de Catalunya, Barcelona, 1999.

COSTA MORATA, P. y BAÑOS PÁEZ, P. "Sociología e ideología de los residuos radiactivos: la sociedad contra la técnica", Argumentos de Razón Técnica, núm.13, 2010, pp. 137-158. 
DEL MORAL, F., y PITA, M. M., "El papel de los riesgos en las sociedades contemporáneas", Cantos, O. y Carcedo, A., Riesgos naturales, Ayala, Barcelona, 2002, pp. $75-88$.

DEWEY, J., La opinión pública y sus problemas, Morata, Madrid, 2004 [1927].

DOMÉNECH PASCUAL, G., "La energía nuclear en un Estado social y democrático de derecho", Doménech Pascual, G. (coord.), El futuro de la energía nuclear en España. Perspectivas (no) sólo jurídicas, Tirant Lo Blanch, Valencia, 2013.

DRNAS DE CLEMENT, Z., "La práctica argentina en materia de sustentabilidad ambiental a través de la aplicación del principio de precaución”, El principio de precaución ambiental. La práctica argentina (proyecto de investigación), Lerner, Córdoba, Argentina, 2006.

ESPEJO MARÍN, C., "La producción de electricidad de origen nuclear en España", Boletín de la A.G.E., núm. 33, 2002, pp. 65-77.

ESTEVE PARDO, J., Técnica, riesgo y derecho, Ariel, Barcelona, 1999.

- “Convivir con el riesgo. La determinación del riesgo permitido", Arana García, E., Mercado Pacheco, P., Pérez Alonso, E., y Serrano Moreno, J. L., Derecho, Globalización y Medio Ambiente, Tirant Lo Blanch, Valencia, 2012.

- "Las decisiones normativas sobre riesgos nucleares. Marco constitucional", Doménech Pascual, G. (coord.), El futuro de la energía nuclear en España. Perspectivas (no) sólo jurídicas, Tirant Lo Blanch, Valencia, 2013.

- El desconcierto del Leviatán. Política y derecho ante las incertidumbres de la ciencia, Marcial Pons, Madrid, 2009.

FERNÁNDEZ-SOLA, N., "Una respuesta multilateral a la proliferación nuclear: las perspectivas de la conferencia de revisión de 2010 del Tratado de No Proliferación Nuclear", Anuario de derecho internacional $X X V$, Servicio de Publicaciones de la Universidad de Navarra, pp. 319 a 345.

GARRIDO CORDOBERA, L. M. R., El riesgo ambiental, Reus, Madrid, 2014.

GIDDENS, A., The Third Way. The Renewal of Social Democracy, Polity Press, Cambridge, 1998.

GONZÁLEZ ROMERO, E. M., y RUIZ HERNÁNDEZ, V., Energía nuclear, CSIC, Madrid, 2010. 
HÄRBELE, P., “Un derecho constitucional para las futuras generaciones. La otra forma del contrato social: el contrato generacional”, Lecciones y Ensayos, núm. 87, 2009, pp. 17-37.

JARIA I MANZANO, J., "El fundamento constitucional de los derechos de participación en materia de medio ambiente y su desarrollo en la Ley 27/2006", Pigrau Solé, A., Acceso a la información, participación púbica y acceso a la justicia en materia de medio ambiente: diez años del Convenio de Aarhus, Atelier, Barcelona, 2009.

- La cuestión ambiental y la transformación de lo público, Tirant Lo Blanch, Valencia, 2011.

JONAS, H., El principio de responsabilidad: ensayo de una ética para la civilización tecnológica, Herder, Barcelona, 1995.

LAGO CANDEIRA, A. y LOZANO CUTANDA, B., "El derecho ambiental de la Unión Europea", Lozano Cutanda, B. (dir.), Tratado de derecho ambiental, CEF, Madrid, 2014.

LÓPEZ ARNAL, S. y RODRÍGUEZ FARRÉ, E., Casi todo lo que usted desea saber sobre los efectos de la energía nuclear en la salud y el medio ambiente, Ediciones El Viejo Topo, España, 2008, pp. 40 a 41.

LUJÁN, J. L. y TODT, O., “Ciencia precautoria y la fabricación de incertidumbre”, proyecto "El principio de precaución en la evaluación de riesgos", MEC, presentado en el V Congreso de la Sociedad de Lógica, Metodología y Filosofía de la Ciencia en España, Granada, 2006.

MARTÍNEZ NEGRETE, M. A., "La carrera armamentista nuclear en el umbral del siglo XXI”, Revista Ciencias - Universidad Autónoma de México, núm. 33, eneromarzo, 1994.

MELLADO JIMÉNEZ, I., "Renovación de las autorizaciones de explotación de las centrales nucleares", Doménech Pascual, G. (coord.), El futuro de la energía nuclear en España. Perspectivas (no) sólo jurídicas, Tirant Lo Blanch, Valencia, 2013, pp. 59-68.

MENDOZA BUERGO, B., "El derecho penal ante la globalización. El papel del principio de precaución", Bacigalupo, S., Derecho Penal y Política Transnacional, Atelier, Barcelona, 2005. 
MEYER-ABICH, K. M., "Von der Wohlstandsgesellschaft zur Risikogesellschaft", Aus Politik und Zeitgeschichte, vol. 36, 1989.

NOVAK, S. y PODEST, M., "Envejecimiento y prolongación de la vida útil de las centrales nucleares: aspectos de seguridad", Visión general de las cuestiones pertinentes y celebración del simposio del OIEA, 1987.

PERROW, C., Normal Accidents: Living with High Risk Technologies, Basic Books, Nueva York, 1984.

RUIZ DE APODACA, A., "Nuevas perspectivas del Derecho Nuclear en Europa y en España", Revista electrónica del Departamento de Derecho de la Universidad de La Rioja, núm. 9, 2011, pp. 67 a 98.

- "Instalaciones nucleares: ponderación de riesgos y necesaria participación en los procesos autorizados", Arana García, E., Mercado Pacheco, P., Pérez Alonso, E. y Serrano Moreno, J. L., Derecho, Globalización y Medio Ambiente, Tirant Lo Blanch, Valencia, 2012.

- "El marco jurídico actual de la energía nuclear en España”, Doménech Pascual, G. (coord.), El futuro de la energía nuclear en España. Perspectivas (no) sólo jurídicas, Tirant Lo Blanch, Valencia, 2013.

SCHWABE,J., Jurisprudencia del Tribunal Constitucional Alemán. Extractos de las sentencias más relevantes, Konrad-Adenauer-Stiftung e. V., Berlín, Alemania, 2009.

SCHWEICKART, D., Más allá del capitalismo, Sal Terrae, Cantabria, 1993 (trad. de Carlos Escriche Blancaflor, 1997).

SERRADELL GARCÍA, V., "Seguridad Nuclear: conceptos y métodos”, ponencia presentada en el curso de la UIMP Seguridad Nuclear y Reactores Avanzados, tomo II, Valencia, julio de 1991.

SERRANO, J., Ciencia + tecnología + sociedad + museos $=$ cómo conseguir que el futuro se parezca a lo que esperamos, Trea, Madrid, 2013.

SHRADER-FRECHETTE, K.S., Energía nuclear y bienestar público, Alianza, Madrid, 1980.

STIRLING, A; RENN, O; KLINKE, A; RIP, A. \& SALO, A., "On science and precaution in the management of technological risk", Technological Risk and Management of Uncertainty, Report ESTO/SPRU, Sussex, 1999. 
SUNSTEIN, C. R., Leyes del miedo. Más allá del principio de precaución, Katz, Madrid, 2005.

VILLAMARINO SAMALEA, G., "Derecho de residuos radiactivos y medio ambiente", Documentación administrativa, núm. 256, 2000. 